\title{
Centrifuge tests on strip footings on sand with a weak layer
}

1 Maurizio Ziccarelli PhD Assistant Professor, Dipartimento di Ingegneria Civile, Ambientale, Aerospaziale, dei Materiali, Università degli Studi di Palermo, Palermo, Italy

2 Calogero Valore

Full Professor, Dipartimento di Ingegneria Civile, Ambientale, Aerospaziale, dei Materiali, Università degli Studi di Palermo, Palermo, Italy
3 Sandro Rino Muscolino PhD

Research Fellow, Dipartimento di Ingegneria Civile, Ambientale, Aerospaziale, dei Materiali, Università degli Studi di Palermo, Palermo, Italy

4 Vincenzo Fioravante $\mathrm{PhD}$

Full Professor, Dipartimento di Ingegneria, Università degli Studi di Ferrara, Ferrara, Italy
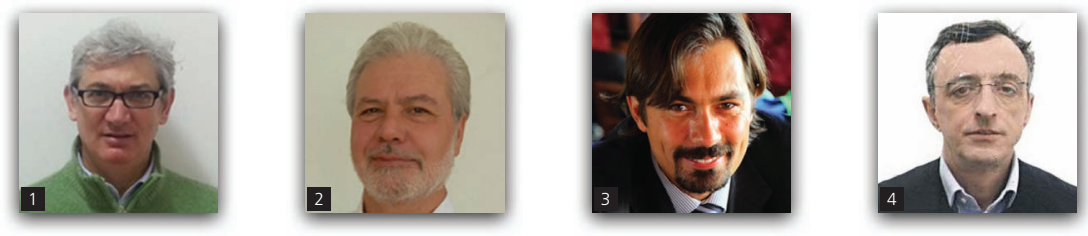

Tests on small-scale physical models of a strip footing resting on a dense sand bed containing a thin horizontal weak soil layer were carried out at normal gravity $(1 \mathrm{~g})$. The results, reported in a companion paper, point out that the weak layer plays an important role in the failure mechanism and the ultimate bearing capacity of the footing if it falls within the ground volume relevant to the behaviour of the sand-footing system. The same problem was also investigated by means of centrifuge tests on reduced-scale models at $25 \mathrm{~g}$ and $40 \mathrm{~g}$. The results of these tests, reported and discussed in this paper, confirm that failure mechanisms are governed substantially by the presence of the weak layer if its depth does not exceed a critical value and highlight marked scale effects involving the ultimate bearing capacity related essentially to the mean equivalent stress level in the soil beneath and around the footing. Equivalent bearing capacity factors, $\boldsymbol{N}_{\gamma}^{*}$, for footings on a dense sand bed containing a thin weak layer are derived from experimental results and are proposed in the paper.

\section{Notation}

$B \quad$ footing width

$B_{\mathrm{m}} \quad$ base width of model

$B_{\mathrm{p}} \quad$ base width of prototype

$C_{\mathrm{U}} \quad$ uniformity coefficient

$c_{1 \mathrm{p}}^{\prime} \quad$ cohesion intercept of sand

$D_{\mathrm{r}} \quad$ relative density

$d \quad$ particle diameter

$d_{50} \quad$ mean particle size

$E^{\prime} \quad$ Young's modulus

e void ratio

$e_{0} \quad$ initial void ratio

$e_{\max }$ maximum void ratio

$e_{\min }$ minimum void ratio

$G_{\text {s1 }} \quad$ specific gravity of sand

g gravity acceleration

$K_{0} \quad$ coefficient of Earth pressure at rest

$L \quad$ footing length

$l_{\mathrm{m}} \quad$ lateral extent of failure mechanism

$N \quad$ ratio between the centrifuge test and gravity accelerations porosity

$n_{0} \quad$ initial porosity

Q $\quad$ vertical load applied to the footing

$q \quad$ mean vertical pressure acting on the footing base $q_{\text {lim }}$

$q_{\text {lim,o }}$

$t_{0}$

$Z_{i}$

$Z_{\mathrm{m}}$

$\gamma_{\mathrm{d} 1}$

$\gamma_{\mathrm{d} 2}$

$\gamma_{\mathrm{s} 1}$

$\delta^{\prime}$

$\delta_{1}^{\prime}$

$\theta$

$v^{\prime}$

$\rho$

$\rho^{*}$

$\rho_{\text {lim }}$

$\sigma^{\prime}$

$\sigma_{\mathrm{v}}^{\prime}$

$\tau$

$\phi_{1}^{\prime}$

$\phi_{1 \mathrm{cv}}^{\prime} \quad$ angle of shearing resistance of sand at constant volume

(or at critical porosity)

ultimate (or limit) bearing pressure (at peak) or ultimate bearing capacity

ultimate bearing pressure (at peak) of footing on homogeneous sand bed

thickness of weak layer

depth from the ground surface of the weak layer

depth from the ground surface of the deepest point of the failure mechanism

dry weight of sand

dry unit weight of weak layer

specific weight of sand

angle of shearing resistance of the footing-sand interface angle of friction of the glass-sand interface emersion angle of the failure surface; $\theta_{\mathrm{L}}$ and $\theta_{\mathrm{R}}$ on the left and right sides of the footing, respectively

Poisson's ratio

settlement of the footing

density (or volumic mass)

settlement of the footing in correspondence of $q_{\mathrm{lim}}$ normal effective stress

vertical effective stress

shear stress

angle of shearing resistance of sand 
Centrifuge tests on strip footings on sand

with a weak layer

Ziccarelli, Valore, Muscolino and Fioravante $\phi_{1 \mathrm{p}}^{\prime} \quad$ peak angle of shearing resistance of sand

$\phi_{1 \mathrm{p}}^{\prime *} \quad$ mean equivalent angle of shearing strength

$\phi_{2 \mathrm{p}}^{\prime} \quad$ angle of shearing resistance of the weak layer

$\psi_{1 \mathrm{p}}^{\prime} \quad$ peak dilation angle of sand

\section{Introduction}

Minor geological and geotechnical details can have great relevance for seepage and consolidation processes as well as for the movements and stability of natural and manmade geotechnical systems (Leonards, 1982; Rowe, 1972; Terzaghi, 1929). The simplest of such details is probably exemplified by a thin horizontal weak soil layer interbedded in a mass of stiffer soil. This problem was recently investigated with reference to the ultimate bearing capacity of strip footings by $1 \boldsymbol{g}$ small-scale model tests discussed in a companion paper (Valore et al., 2017).

These tests highlighted that the weak layer, despite its thinness, can markedly affect the failure mechanism and significantly reduce the ultimate bearing capacity. However, it is well known that $1 g$ tests on reduced-scale models suffer from severe limitations due to scale effects associated, first of all, with the very low stresses in the granular soil of the model (e.g. de Beer (1965), Vesić (1975), Kimura et al. (1985), Bolton and Lau (1989), Kusakabe et al. (1991), Ueno et al. (2001), Zhu et al. (2001), Lau and Bolton (2011a)).

To investigate scale effects on failure mechanisms and on the bearing capacity, centrifuge experiments at enhanced gravity of $25 \mathrm{~g}$ and $40 \mathrm{~g}$ were carried out. It is well known that these kinds of tests also serve the important purpose of providing reliable physical data to verify numerical methods as clearly pointed out by $\mathrm{Ng}$ (2014). Ten centrifuge tests were performed.

The problem dealt with can be schematised with reference to the front view of the reduced-scale model shown in Figure 1. The strip footing is a rigid punch and rests on the surface of a dry

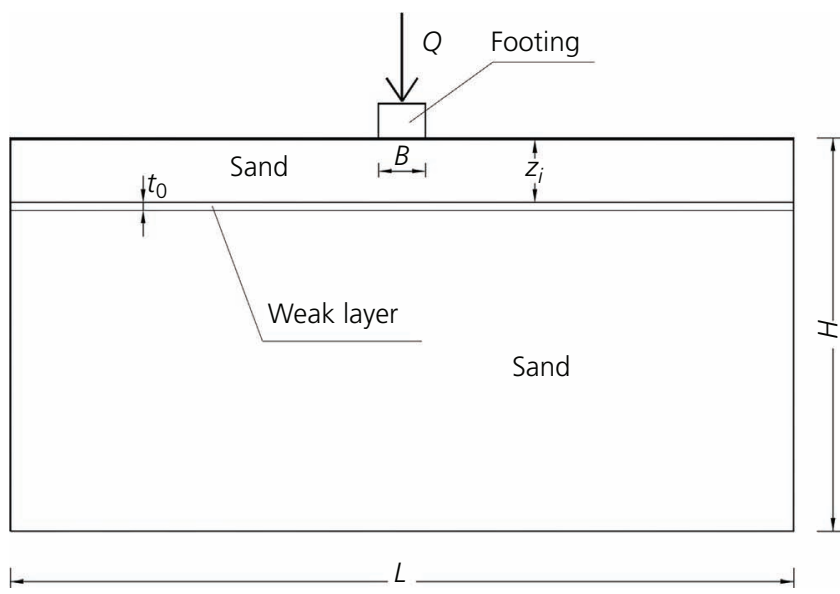

Figure 1. Scheme for the formulation of the problem sand mass in which a thin horizontal layer, $t_{0}$ thick, made of a weaker material than sand, is interposed at depth $z_{i}$. Plane strain conditions are assumed.

The results of the tests are reported and discussed in the present paper.

\section{Instrumentation}

\section{Centrifuge}

The small-scale model tests were carried out using the Istituto Sperimentale Modelli Geotecnici (ISMGeo) seismic geotechnical centrifuge, which is a beam centrifuge made up of a symmetrical rotating arm with a diameter of $6 \mathrm{~m}$, a height of $2 \mathrm{~m}$ and a width of $1 \mathrm{~m}$, which gives it a nominal radius of $2 \mathrm{~m}$. The arm holds two swinging platforms, one used to carry the model container and the other the counterweight. During the tests, the platforms lock horizontally onto the arm to prevent the transmission of the working loads to the basket suspensions. An outer fairing covers the arm; the arm and fairing concurrently rotate to reduce air resistance and perturbations during flight. The centrifuge has the potential of reaching an acceleration of $600 \mathrm{~g}$ at a payload of $400 \mathrm{~kg}$. Further details can be found in the papers of Baldi et al. (1988), Fioravante (1999) and Fioravante et al. (2012). The dimensions of the tested models are length $=0.62 \mathrm{~m}$, height $=$ $0 \cdot 28 \mathrm{~m}$ and width $=0 \cdot 16 \mathrm{~m}$.

A picture of a model at the end of a test is shown in Figure 2.

\section{Load application}

The axial load is applied by a mechanical actuator that pushes the footing into the sand at a constant rate of displacement of $0.5 \mathrm{~mm} / \mathrm{min}$. The load is measured by a $50 \mathrm{kN}$ hydraulic cell.

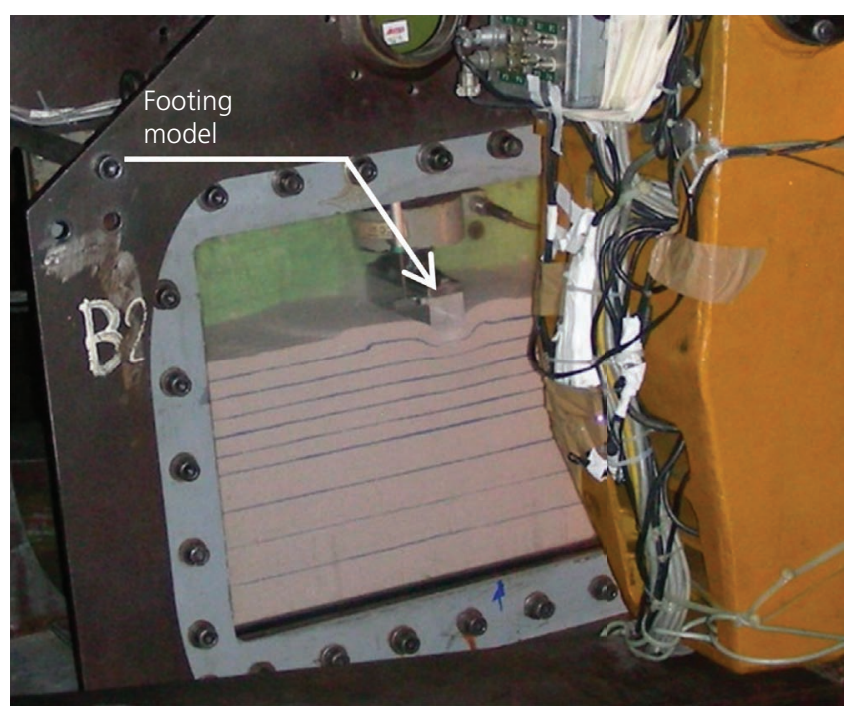

Figure 2. The physical model fixed to the basket at rest after the conclusion of a test 


\section{Data acquisition system and measurements}

Data are recorded by an automatic six-channel system, with an acquisition frequency of one record every $2 \mathrm{~s}$. The radial acceleration is measured by a piezoresistive accelerometer. The settlement of two opposite vertices of the top face of the footing and of a point of the soil surface located at a distance from the centroid of the footing base of $17 \cdot 8 \mathrm{~cm}$ (equal to $4 \cdot 45 \mathrm{~B}$ ) are measured by means of linear displacement transducers (LDTs). Images of the frontal face of the model are taken through a poly(methyl methacrylate) (PMMA) window by a video-recording colour digital camera.

\section{Model preparation}

The model was prepared in the ISMGeo geotechnical laboratory adjoining the centrifuge room and then placed aboard the centrifuge.

\section{Sand}

The foundation soil, apart from the weaker layer, consists of silica sand and is hereafter called sand B. The sand grains are subrounded to angular. Each soil model was reconstituted at $1 \boldsymbol{g}$ to the target void ratio by pluviating, in air, the dry sand into a rigid container by using a travelling sand spreader. The target density was obtained by calibrating the height of fall and the size of the spreader hole. The height of fall of $1 \mathrm{~m}$ was kept constant during the deposition in order to achieve uniformity of the soil density within the sand bed. The main characteristics of sand B are summarised in Table 1 , where the average void ratio, $e_{0}$, the porosity, $n$, dry density, $\gamma_{\mathrm{d} 1}$ and relative density, $D_{\mathrm{r}}$ of the models before acceleration are also indicated.
From the mineralogical point of view, sand B is essentially composed of silica (more than 95\%). There are, however, traces of feldspars and calcite.

In order to compare the results of $1 \boldsymbol{g}$ and centrifuge tests and to study the scale effects, sand B was also used in $1 g$ tests on $40 \mathrm{~mm}$ wide footings (Valore et al., 2017), according to a wellestablished practice (Altaee and Fellenius, 1994; Kimura et al., 1985; Schofield, 1980; Toyosawa et al., 2013; Yamaguchi et al., 1977). It is worth noting that the ratio of the footing width to the mean particle size, $B / d_{50}=40 / 0 \cdot 45=88 \cdot 9$, is larger than 50 , which is the minimum value beyond which the particle size effect can be considered negligible, as suggested by many researchers (e.g. Mikasa and Takasa (1973), Ovesen (1975), Gemperline and Ko (1984), Kutter et al. (1988), Tatsuoka et al. (1991), Kusakabe (1995), Herle and Tejchman (1997), Toyosawa et al. (2013)).

The crushing of the sand particles during the tests has been considered negligible due to the grading and the mineralogy of the sand and the mean stress level existing in the soil volume involved in failure (Valore and Ziccarelli, 2009).

The peak strength failure envelope of sand $\mathrm{B}$, obtained from direct shear tests on dry sand (Figure 3), is strongly curvilinear in the range of low normal stresses. For very low normal stresses, the shear strength parameters vary as follows: $c_{1 \mathrm{p}}^{\prime}=0$ and $\phi_{1 \mathrm{p}}^{\prime}>50^{\circ}$ for $\sigma^{\prime}<20 \mathrm{kPa} ; c_{1 \mathrm{p}}^{\prime}=0$ and $\phi_{1 \mathrm{p}}^{\prime}=50^{\circ}$ for $\sigma^{\prime}<50 \mathrm{kPa}$; and $c_{1 \mathrm{p}}^{\prime}=0$ and $\phi_{1 \mathrm{p}}^{\prime}=45^{\circ}$ for $\sigma^{\prime}>50 \mathrm{kPa}, \phi_{1 \mathrm{p}}^{\prime}$ being the secant angle of shearing resistance. The relation between $\phi_{1 \mathrm{p}}^{\prime}$ and the normal effective stress,

Table 1. Characteristics and initial index properties of sand B

\begin{tabular}{|c|c|c|c|c|c|c|c|c|c|c|c|c|}
\hline$G_{\mathrm{s} 1}$ & $\gamma_{\mathrm{s} 1}: \mathrm{kN} / \mathrm{m}^{3}$ & $e_{0}$ & $n_{0}$ & $\boldsymbol{e}_{\min }$ & $e_{\max }$ & $D_{\mathrm{r}}: \%$ & $\gamma_{\mathrm{d} 1}: \mathrm{kN} / \mathrm{m}^{3}$ & $d_{\max }: m m$ & $d_{60}: m m$ & $d_{50}: \mathrm{mm}$ & $d_{10}: \mathrm{mm}$ & $C_{U}=d_{60} / d_{10}$ \\
\hline 2.65 & 26 & 0.647 & 0.393 & 0.634 & 0.897 & 95 & $15 \cdot 8$ & 0.85 & 0.47 & 0.45 & 0.33 & 1.42 \\
\hline
\end{tabular}

Minimum and maximum void ratios were determined according to ASTM standards D 4253-00 (ASTM, 2004a) and D 4254-00 (ASTM, 2004b)

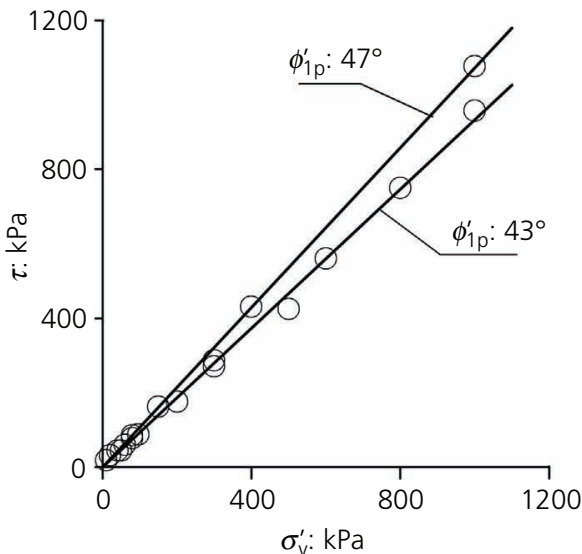

(a)

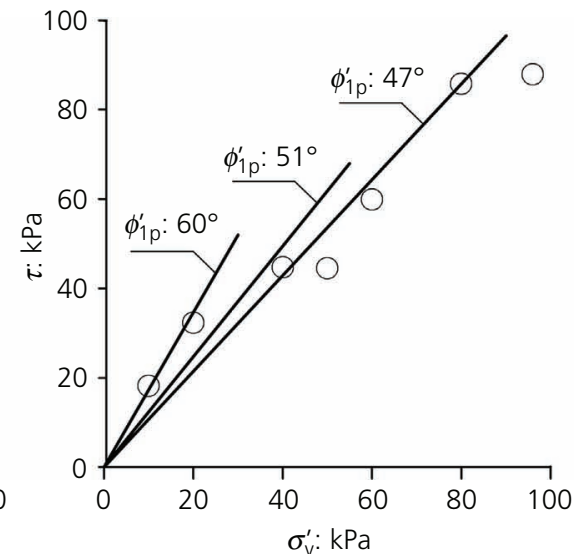

(b)

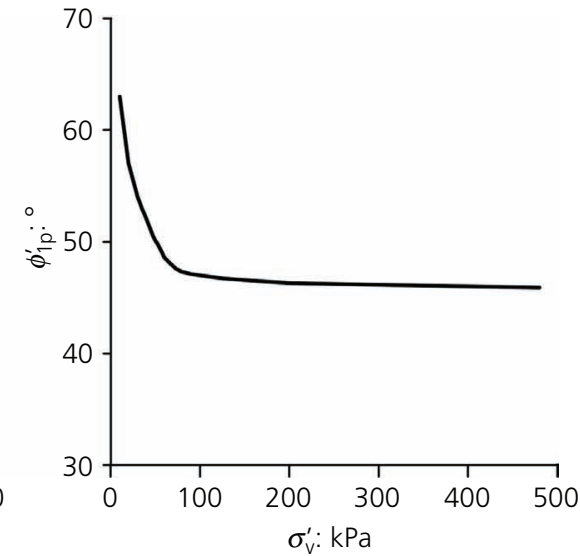

(c)

Figure 3. Peak strength failure envelope from direct shear results on dry silica sand B: (a) all tests and (b) tests at low stresses. (c) Secant angle of peak shearing resistance $\phi_{1 p}^{\prime}$ as a function of the effective vertical normal stress $\sigma_{v}^{\prime}$ 
$\sigma_{\mathrm{v}}^{\prime}$, is shown in Figure 3(c). The peak dilation angle, $\psi_{1 \mathrm{p}}^{\prime}$, was obtained from the results of direct shear tests and decreases with normal stress, $\sigma_{\mathrm{v}}^{\prime}$. Within the range of $\sigma_{\mathrm{v}}^{\prime}$ relevant to the present research, $\psi_{1 \mathrm{p}}^{\prime}$ varies from 17 to $21^{\circ}$ and is in good agreement with Bolton's relation: $\psi_{1 \mathrm{p}}^{\prime}=1.25\left(\phi_{1 \mathrm{p}}^{\prime}-\phi_{1 \mathrm{cv}}^{\prime}\right)$ (Bolton, 1986). The angle of shearing strength at constant volume $\phi_{1 \mathrm{cv}}^{\prime}$ is $32^{\circ}$.

The average values of peak strength parameters at the average stresses relevant to the models tested in the centrifuge, modified for the effects of the intermediate effective principal stress for plane strain conditions (Meyerhof, 1951; Roscoe, 1970; Rowe, 1969; Tatsuoka et al., 1986a, 1986b), are summarised in Table 2.

\section{Materials of the weak layer}

The material used for the weak layer is the 'CM3' dry talc powder that was also used in tests at single gravity (Valore et al., 2017). The angle of peak shear strength, $\phi_{2 p}^{\prime}$, of this material was determined by direct shear tests and is equal to $27^{\circ}$. The cohesion intercept and dilation angles of the CM3 talc powder are negligible. The initial (i.e. before centrifuge testing) weak layer thickness was $5 \mathrm{~mm}$.

\section{Footing}

The footing is made of aluminium and can be considered rigid; its width, $B$, and length, $L$, are 40 and $160 \mathrm{~mm}$, respectively. Sandpaper was glued onto the footing base. The settlements of the footing are uniform. The peak angle of shearing resistance, $\delta^{\prime}$, of the interface between the silica sand and the sandpaper was $42^{\circ}$ (Valore et al., 2017). As the average peak shearing resistance angle, $\phi_{1 \mathrm{p}}^{\prime}$, of silica sand was about $48^{\circ}$ at the stress level relevant to the model tests, the sand-footing contact can be considered perfectly rough (Hansen and Christensen, 1969; Kumar and Kouzer, 2007), since $\delta^{\prime} / \phi_{1 \mathrm{p}}^{\prime}>0.7$ (Fioravante, 2002; Garnier and König, 1998; Kishida and Useugi, 1987; Lings and Dietz, 2005)

The values of the base width of the models $\left(B_{\mathrm{m}}\right)$ and prototypes $\left(B_{\mathrm{p}}\right)$ are summarised in Table 3.

\section{PMMA-sand friction}

To minimise the friction, the sand-PMMA interface was lubricated with silicone oil. Although the PMMA-sand friction is not nil, it is believed that the actual deformation state can be approximately considered two dimensional.

\section{Model formation}

The sand was poured into the test box by using the dry pluviation procedure. Through a proper apparatus with a $2 \mathrm{~mm}$ slit, a

Table 2. Shear strength parameters of sand B for plane strain conditions

$\begin{array}{lccc}c_{1 \mathrm{p}}^{\prime}: \mathrm{kPa} & \phi_{1 \mathrm{p}}^{\prime}:^{\circ} & \phi_{1 \mathrm{cv}}^{\prime}:^{\circ} & \psi_{1 \mathrm{p}}^{\prime}:^{\circ} \\ 0 & 46-49 & 32 & 17-21\end{array}$

$\psi_{1}^{\prime}$, peak dilation angle horizontal speed of $10 \mathrm{~cm} / \mathrm{s}$ and a constant fall height of $100 \mathrm{~cm}$, it was possible to obtain a dry soil with a uniform initial unit weight, $\gamma_{1 \mathrm{~d}}$, of $15 \cdot 8 \mathrm{kN} / \mathrm{m}^{3}$. The weak layer was formed with dry talc powder (type CM3). It was formed by pouring a known weight of talc powder into the test box, and then it was gently compressed by means of a flat wooden pestle in order to obtain a regular layer $5 \mathrm{~mm}$ thick.

\section{Testing procedure}

The following sequence was used.

- The centrifuge was accelerated up to the selected acceleration, $a(25 g$ or $40 g)$; in this phase, the footing was suspended over the soil.

- The soil model densification due to self-weight at constant acceleration was monitored.

- At the end of the in-flight densification (i.e. end of soil surface settlement, as measured by an LDT), a deceleration/ acceleration cycle of $a / 2$ (half of testing acceleration) was carried out. At the end of this phase, the settlement of the top surface of the homogeneous sand bed was $0.5 \mathrm{~cm}$ for both tests at $25 \mathrm{~g}$ and $40 \mathrm{~g}$. This settlement implies an increase in the dry unit weight from $15 \cdot 8$ to $16 \cdot 1 \mathrm{kN} / \mathrm{m}^{3}$.

- The footing was gently lowered until contact with the model surface was achieved. The loading test was then performed. The footing was pushed at a constant rate of displacement of about $0.5 \mathrm{~mm} / \mathrm{min}$, and the axial load $Q$ was measured by a load cell until the failure load was attained (ultimate bearing capacity). Subsequently, the loading continued until a settlement of about $25 \mathrm{~mm}(\approx 0.6 B)$ was attained.

The duration (after the start of the loading proves) of each test ranged from 15 to $40 \mathrm{~min}$.

The homogeneous sand bed test and the tests on sand containing a weak layer made of dry talc powder were, of course, drained since both the sand and the talc were dry.

\section{Results}

The results of tests are summarised in Tables 4 and 5 for $a=25 g$ $(N=a / g=25)$ and $a=40 \boldsymbol{g}(N=40)$, respectively.

\section{Faillure mechanisms}

Observed failure mechanisms are sketched in Figure 4 for tests at $25 \boldsymbol{g}(N=25)$ and in Figures 5 and 6 for tests at $40 \boldsymbol{g}(N=40)$. Some photographs of the models are shown in Figures 7 and 8 .

Table 3. Widths of the bases of footings for models $\left(B_{\mathrm{m}}\right)$ and prototypes $\left(B_{\mathrm{p}}\right)$

$\begin{array}{|cccc|}\boldsymbol{N} & \boldsymbol{a} & \boldsymbol{B}_{\mathbf{m}}: \mathbf{m} & \boldsymbol{B}_{\mathbf{p}}: \mathbf{m} \\ 1 & 1 \boldsymbol{g} & 0.04 & 0.04 \\ 25 & 25 \boldsymbol{g} & 0.04 & 1.00 \\ 40 & 40 \boldsymbol{g} & 0.04 & 1.60\end{array}$


Geotechnical Research

Volume 4 Issue GR1
Centrifuge tests on strip footings on sand

with a weak layer

Ziccarelli, Valore, Muscolino and Fioravante

Table 4. Results of centrifuge tests performed at acceleration $a=25 \mathrm{~g}$ on strip footing models resting on a sand bed containing a thin horizontal weak layer

\begin{tabular}{|c|c|c|c|c|c|c|c|c|c|c|c|c|c|}
\hline Weak layer & Test & $z_{i} / B_{m}$ & $t_{0}: \mathrm{mm}$ & $I_{\mathrm{m}}: \mathrm{mm}$ & $I_{m} / B_{m}$ & $z_{\mathrm{m}}: \mathrm{mm}$ & $z_{m} / B_{m}$ & $\theta_{L}:^{\circ}$ & $\theta_{\mathrm{R}}:^{\circ}$ & $q_{\text {lim }}: \mathbf{k P a}$ & $q_{\lim } / q_{\lim , 0}$ & $\rho_{\mathrm{m}, \mathrm{lim}}: \mathrm{mm}$ & $\rho_{\mathrm{m}, \mathrm{lim}} / B_{\mathrm{m}}$ \\
\hline \multirow[t]{3}{*}{ Dry CM3 talc powder } & $\mathrm{CO2}$ & 1 & 7 & 106 & $2 \cdot 65$ & 40 & 1.00 & 39 & 36 & $2118 \cdot 2$ & 0.55 & $5 \cdot 39$ & $0 \cdot 13$ \\
\hline & $\mathrm{CO3}$ & 2 & 5 & $161 \cdot 4$ & 4.04 & 80 & $2 \cdot 00$ & 36 & - & $2413 \cdot 9$ & 0.62 & $5 \cdot 95$ & 0.15 \\
\hline & $\mathrm{CO8}$ & 3 & 5 & $116 \cdot 9$ & 2.92 & $57 \cdot 3$ & $1 \cdot 43$ & - & 39 & $3117 \cdot 3$ & $0 \cdot 81$ & $7 \cdot 09$ & $0 \cdot 18$ \\
\hline Homogeneous sand bed & $\mathrm{C} 01$ & - & - & 104 & $2 \cdot 6$ & 40 & 1 & 30 & 31 & $3869 \cdot 7$ & 1 & $5 \cdot 39$ & $0 \cdot 15$ \\
\hline
\end{tabular}

Results of test C01 on homogeneous sand bed is also reported for comparison

$B_{\mathrm{m}}=40 \mathrm{~mm}$, footing model width; $z_{i}$, depth of the top surface of the weak layer; $t_{0}$, thickness of the weak layer; $q_{\text {lim, }}$ ultimate bearing capacity; $q_{\text {limo }}=3869 \cdot 7 \mathrm{kPa}$, ultimate bearing capacity for the homogeneous sand case; $\rho_{\mathrm{m}, \mathrm{lim}}$, settlement of footing model corresponding to ultimate bearing capacity; $I_{\mathrm{m}}$ maximum lateral extent of failure mechanism; $z_{m}$, maximum depth of failure mechanism; $\theta_{L}$ and $\theta_{R}$, emersion angles of the failure surface on the left and right sides of the footing, respectively

Table 5. Results of centrifuge tests performed at acceleration $\mathrm{a}=40 \mathrm{~g}$ on strip footing models resting on a sand bed containing a horizontal thin weak layer

\begin{tabular}{|c|c|c|c|c|c|c|c|c|c|c|c|c|c|}
\hline Weak layer & Test & $z_{i} / B_{m}$ & $t_{0}: \mathrm{mm}$ & $I_{\mathrm{m}}: \mathrm{mm}$ & $I_{\mathrm{m}} / B_{\mathrm{m}}$ & $z_{m}: m m$ & $z_{m} / B_{m}$ & $\theta_{\mathrm{L}}:^{\circ}$ & $\theta_{\mathrm{R}}:^{\circ}$ & $q_{\text {lim }}: \mathrm{kPa}$ & $q_{\lim } / q_{\lim , 0}$ & $\rho_{\mathrm{m}, \mathrm{lim}}: \mathrm{mm}$ & $\rho_{\mathrm{m}, \mathrm{lim}} / B_{\mathrm{m}}$ \\
\hline \multirow[t]{4}{*}{ Dry CM3 talc powder } & C05 & 1 & 7 & 101 & $2 \cdot 53$ & 40 & $1 \cdot 00$ & 38 & 36 & $2575 \cdot 1$ & 0.52 & $5 \cdot 38$ & 0.13 \\
\hline & C06 & 2 & 7 & 179 & $4 \cdot 48$ & 80 & $2 \cdot 00$ & 33 & - & $3163 \cdot 9$ & 0.62 & 5.95 & 0.15 \\
\hline & C07 & 2.95 & 7 & 180 & $4 \cdot 5$ & 71 & 1.77 & - & 40 & $4285 \cdot 1$ & 0.87 & 8.59 & $0 \cdot 21$ \\
\hline & C 10 & 0.5 & 6 & $47 \cdot 3$ & $1 \cdot 18$ & 35 & 0.88 & 46 & 45 & $3144 \cdot 7$ & 0.64 & $7 \cdot 35$ & $0 \cdot 18$ \\
\hline \multirow[t]{2}{*}{ Homogeneous sand bed } & CO4 & - & - & 104 & $2 \cdot 6$ & 63 & 1 & 30 & 31 & $4937 \cdot 2$ & 1 & $6 \cdot 62$ & 0.17 \\
\hline & C09 & - & - & 155 & $3 \cdot 87$ & 57 & 1.43 & - & 39 & 4767 & 1 & $6 \cdot 49$ & $0 \cdot 16$ \\
\hline
\end{tabular}

Results of tests C04 and C09 on homogeneous sand bed also reported for comparison

$B_{\mathrm{m}}=40 \mathrm{~mm}$, footing model width; $z_{i}$, depth of the top surface of the weak layer; $t_{0}$, thickness of the weak layer; $q_{\text {lim, }}$ ultimate bearing capacity; $q_{\text {lim }, 0}=4937 \cdot 2 \mathrm{kPa}$, ultimate bearing capacity for the homogeneous sand case; $\rho_{\mathrm{m} \text { lim, }}$ settlement of footing model corresponding to ultimate bearing capacity; $I_{\mathrm{m}}$ maximum lateral extent of failure mechanism; $z_{m}$, maximum depth of failure mechanism; $\theta_{L}$ and $\theta_{R}$, emersion angles of the failure surface on the left and right sides of the footing, respectively

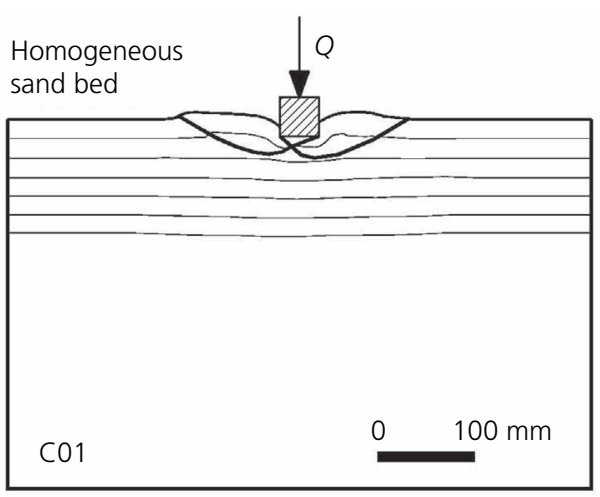

(a)

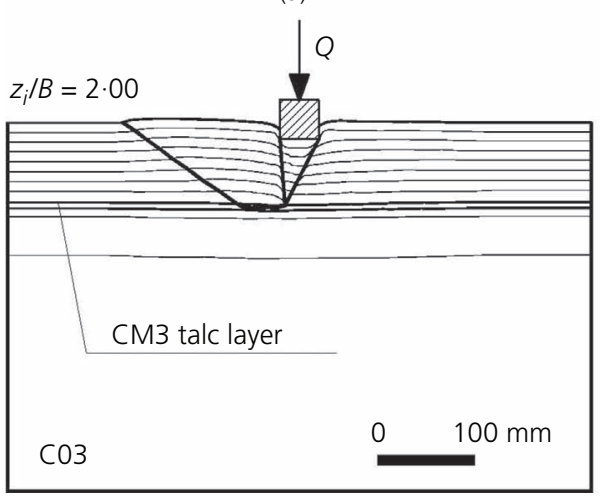

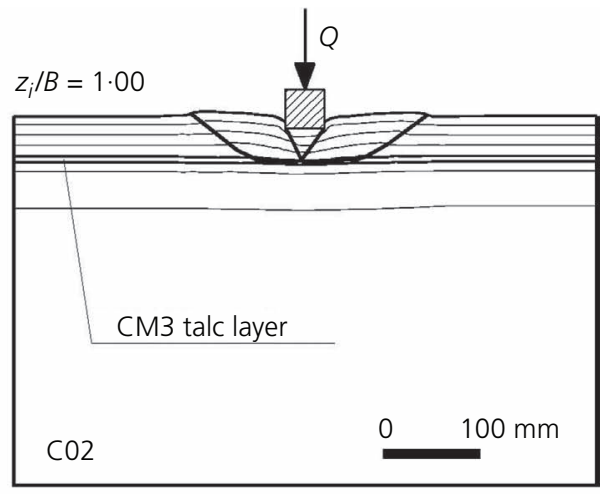

(b)

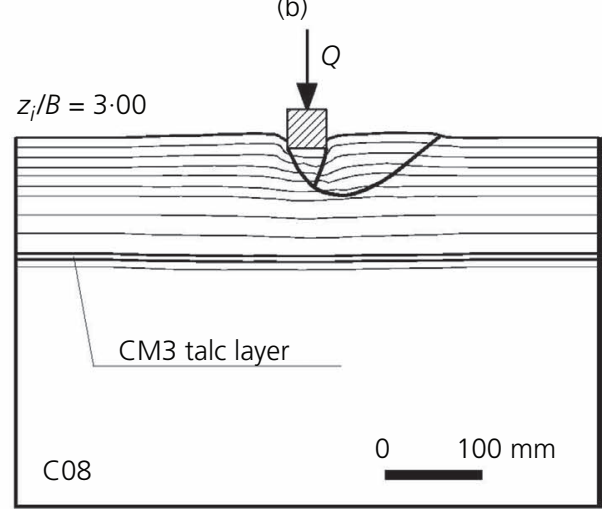

(d)

Figure 4. Failure mechanisms observed in centrifuge tests performed at $25 \mathrm{~g}(N=25)$. $B_{\mathrm{m}}=40 \mathrm{~mm}$. (a) Homogeneous sand bed; (b) ratio $z_{i} / B=1 ;$ (c) $z_{i} / B=2 ;$ (d) $z_{i} / B=3$. The weak layer is shown as double-thickness lines; the thin lines are initially horizontally aligned coloured sand particles 
Centrifuge tests on strip footings on sand

with a weak layer

Ziccarelli, Valore, Muscolino and Fioravante

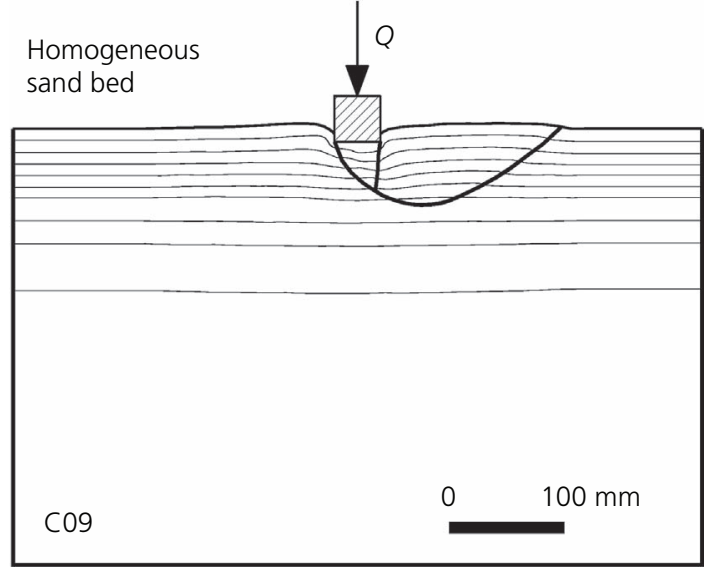

Figure 5. Failure mechanisms observed in centrifuge tests performed at $40 \mathrm{~g}(N=40) . B_{\mathrm{m}}=40 \mathrm{~mm}$. Homogeneous sand bed. Thin lines are initially horizontally aligned coloured sand particles

The photograph of test B63 performed at $1 \mathrm{~g}$ (Valore et al., 2017) is included in Figure 8 for comparison.

General shear failure mechanism (Vesić, 1973) was observed in all experiments. Some observed failure mechanisms were not symmetric. Every effort was made to ensure initial geometric and mechanical symmetry of the tested physical models. But symmetry at the macroscopic scale does not imply an alwaysperfect symmetry at the microscopic level. Non-symmetric mechanisms could originate from initial non-symmetric texture and non-perfectly symmetric distribution of the pores. Results of many physical model experiments on strip footings reported in geotechnical literature yield non-symmetric failure mechanisms, particularly for foundation soil consisting of sands (e.g. Muhs (1965), Yamaguchi et al. (1976), Kimura et al. (1985), Tatsuoka et al. (1991), Kusakabe (1992), Aiban and Znidarčić (1995), Tatsuoka (2001), McMahon and Bolton (2011)). It is worth mentioning that Yamaguchi et al. (1976) discovered nonsymmetry in centrifuge models at $40 \mathrm{~g}\left(B_{\mathrm{m}}=20,30\right.$ and $40 \mathrm{~mm}$, $B_{\mathrm{p}}=0.80,1.2$ and 1.60$)$ using radiography, while Kimura et al. (1985) demonstrated, also by means of X-ray techniques, that at $20 \mathrm{~g}\left(B_{\mathrm{m}}=30 \mathrm{~mm}, B_{\mathrm{p}}=0.6 \mathrm{~m}\right)$ that the slip lines are not symmetric when the base of the footing is rough, while for smooth bases the slip lines are very nearly symmetric.

In the case of the homogeneous sand bed, the failure surfaces resemble that of Prandtl (1920), but their lateral extent is smaller; see Figures 4(a), 5 and 7. Failure surfaces emerge at the ground level at an average angle $\theta$ to the horizontal of about $45^{\circ}-\psi_{1 \mathrm{p}}^{\prime} / 2$. When the weak layer is present, $\theta$ ranges from 33 to $39^{\circ}$ and is
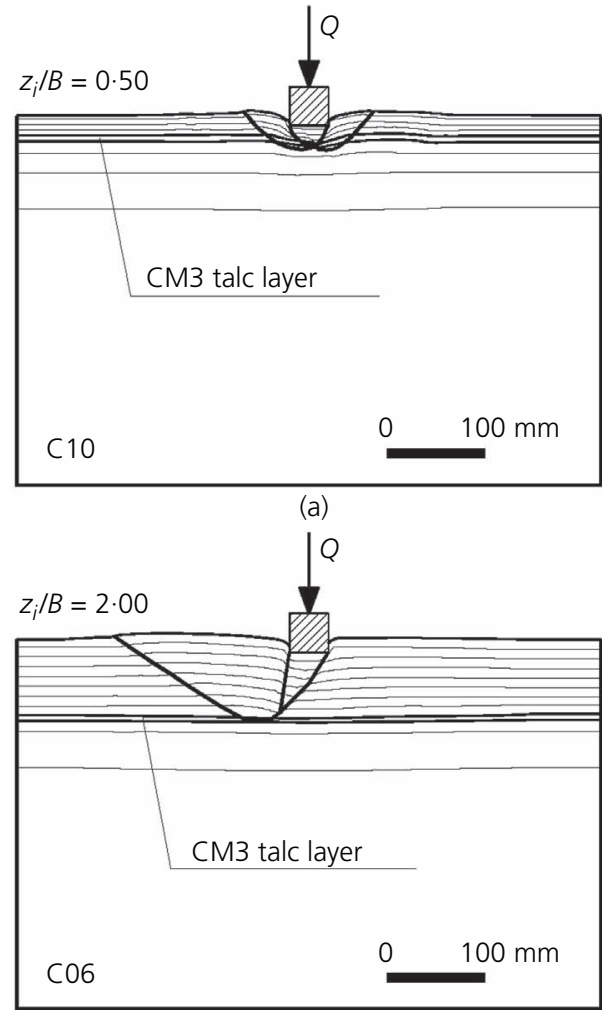

(c)

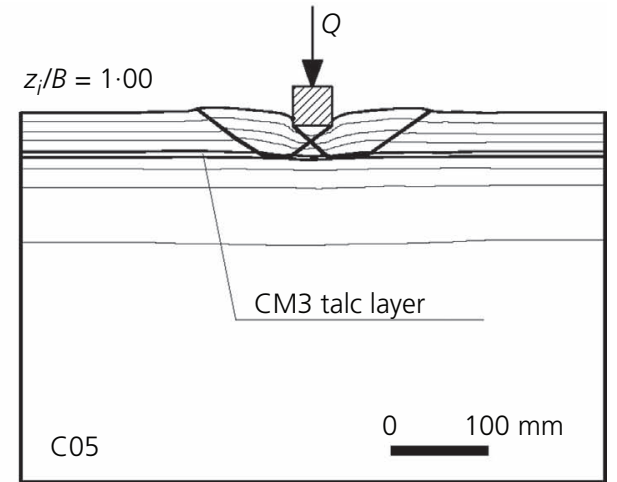

(b)

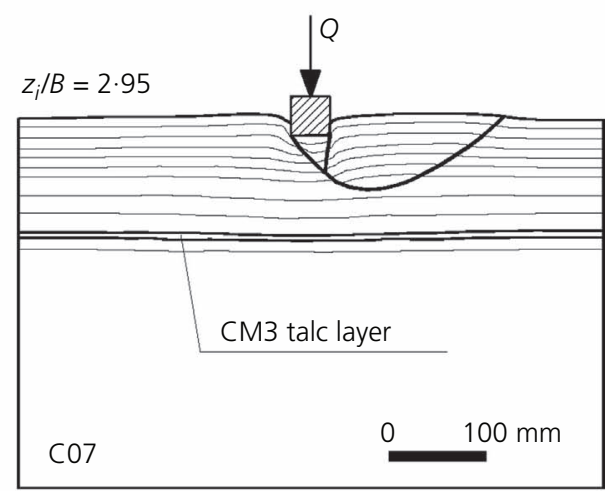

(d)

Figure 6. Failure mechanisms observed in tests performed at $40 \mathrm{~g}(N=40) . B_{\mathrm{m}}=40 \mathrm{~mm}$ : (a) ratio $z_{i} / B=0 \cdot 5$; (b) $z_{i} / B=1$; (c) $z_{i} / B=2$; (d) $z_{i} / B=2 \cdot 95$. The weak layer is shown as double-thickness lines; the thin lines are initially horizontally aligned coloured sand particles 
Geotechnical Research

Volume 4 Issue GR1
Centrifuge tests on strip footings on sand

with a weak layer

Ziccarelli, Valore, Muscolino and Fioravante

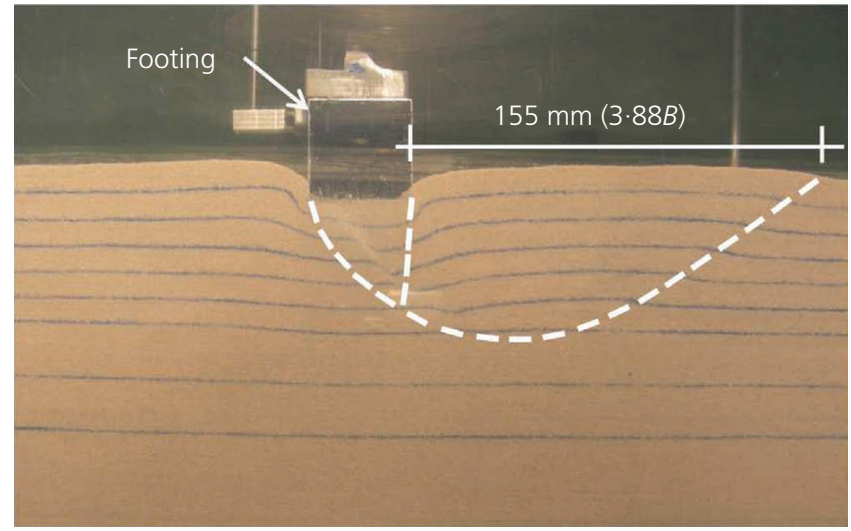

Figure 7. Failure mechanism for footing resting on homogeneous sand bed. Test $C 09$ at $40 \mathrm{~g} \cdot B_{\mathrm{m}}=40 \mathrm{~mm}$

very close to $45^{\circ}-\psi_{1 \mathrm{p}}^{\prime} / 2\left(\psi_{1 \mathrm{p}}^{\prime}=15-20^{\circ}\right)$. The failure surface crosses the weak layer if it is located at depth $z_{i} \leq 0 \cdot 5 B_{\mathrm{m}}$, both at $1 \boldsymbol{g}$ and at enhanced gravity, since its shear strength is high enough to transfer shear stresses to the underlying soil. In contrast, if $z_{i} \geq 3 B_{\mathrm{m}}$, the mechanisms run entirely within the upper sand layer and are almost identical to those pertaining to the homogeneous sand bed but the ultimate bearing capacity is lower than that of the homogeneous case. This difference is probably due to the fact that the stress state, the stress paths and the strain paths in the sand bed with a weak layer differ from the corresponding ones in the homogeneous sand bed. If $0 \cdot 5 B_{\mathrm{m}} \leq z_{i} \leq 3 B_{\mathrm{m}}$, the failure mechanisms run partly along the weak layer. It is to be noted that for a depth of the weak layer of $z_{i} / B=2$, the lateral extension of the failure mechanism relative to the $1 \boldsymbol{g}$ test is greater than that at enhanced gravity (see Figure 8).

The results of centrifuge tests confirm the great influence of the weak layer on failure mechanisms and on ultimate bearing capacity.

\section{Ultimate bearing capacity}

The bearing pressure-normalised settlement curves are shown in Figures 9 and 10 for accelerations of $25 \boldsymbol{g}(N=25)$ and $40 \boldsymbol{g}$ $(N=40)$, respectively. Results of some $1 \boldsymbol{g}$ tests (cf. Valore et al. (2017)) are shown in Figure 11 for comparison.

In all cases, the curves are characterised by a distinct peak corresponding to the ultimate bearing capacity, $q_{\mathrm{lim}}$. Beyond the peak, the applied pressure, $q$, undergoes a conspicuous, but not abrupt, decrease. The normalised settlement, $\rho_{\mathrm{m}, \lim } / B_{\mathrm{m}}$, when the weak layer is lacking, is about 14 and $15.5 \%$ for the centrifuge tests at $25 \mathrm{~g}$ and $40 \mathrm{~g}$, respectively; in the presence of the weak layer, $\rho_{\mathrm{m}, \mathrm{lim}} / B_{\mathrm{m}}$ varies from 14 to $18 \%$, respectively, for the centrifuge tests at $25 \mathrm{~g}$ and from 15 to $21 \%$ for the centrifuge tests at $40 \mathrm{~g}$. The
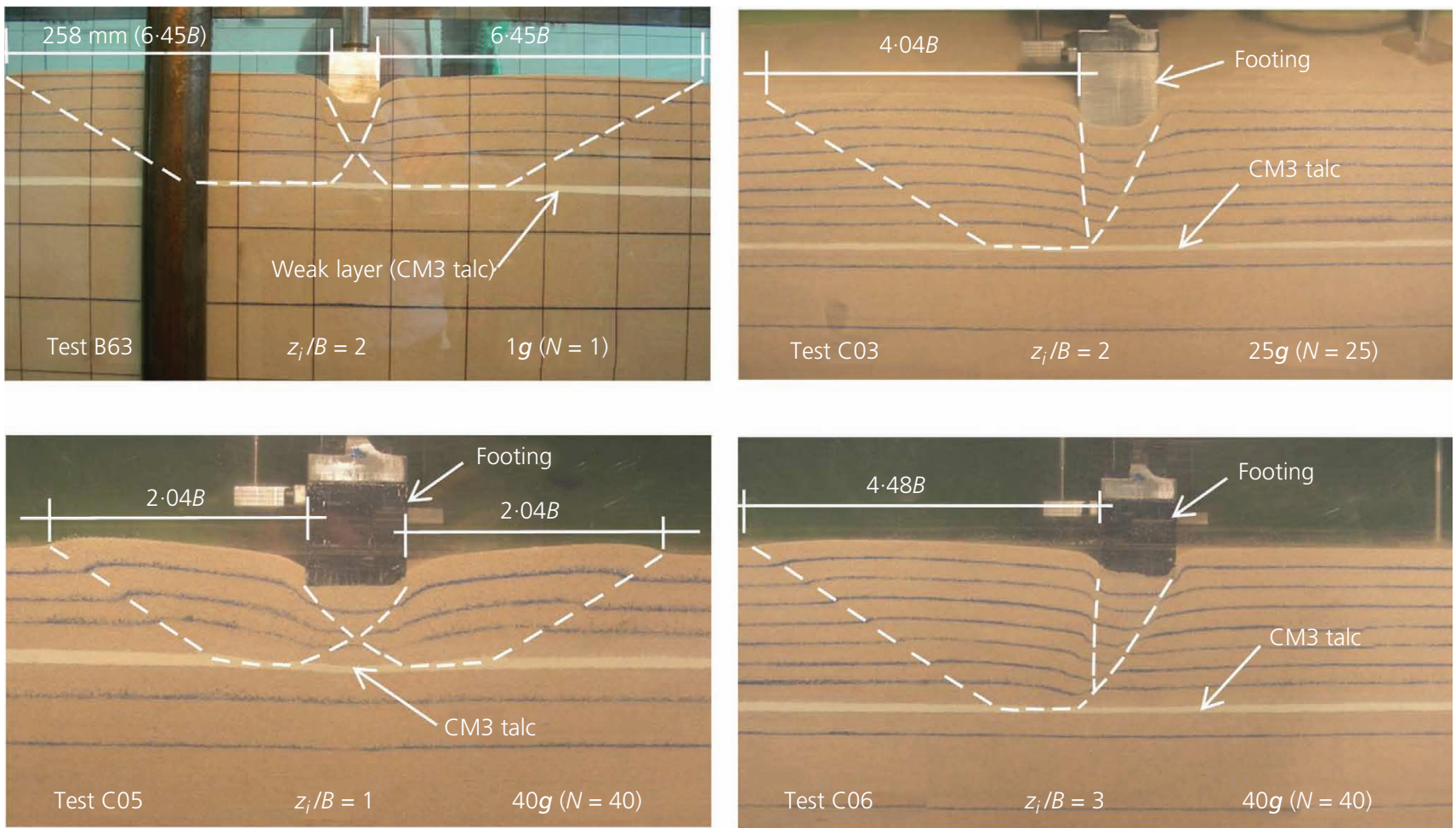

Figure 8. Typical failure mechanisms observed in tests on sand bed containing a weak layer, at $1 \mathrm{~g}$ and at enhanced gravity. $B_{\mathrm{m}}=40 \mathrm{~mm}$. Note that the scales of the photographs are not the same. White broken lines are failure mechanism 
Centrifuge tests on strip footings on sand

with a weak layer

Ziccarelli, Valore, Muscolino and Fioravante

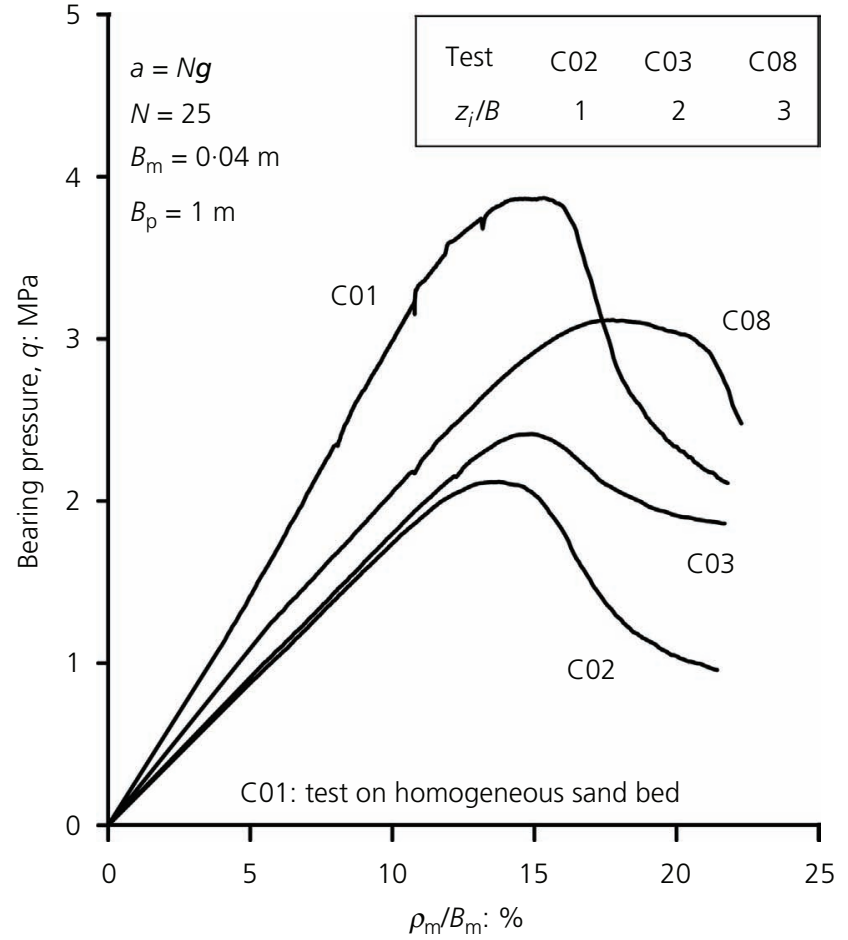

Figure 9. Bearing pressure-normalised settlement curves for tests performed at $a=25 \mathrm{~g}$. Results of test C01 performed on homogeneous sand bed are reported for comparison. $B_{\mathrm{m}}=$ $40 \mathrm{~mm} ; B_{\mathrm{p}}=1 \mathrm{~m} ; z_{i}$, depth of the weak layer. Weak layer made of CM3 talc powder

settlements corresponding to the peak therefore range from about $0 \cdot 15 B_{\mathrm{m}}$ to $0 \cdot 2 B_{\mathrm{m}}$; their influences on $q_{\text {lim }}$ are negligible according to Ovesen (1975), Pu and Ko (1988) and Dijkstra et al. (2013).

The normalised applied pressure, $q / B_{\mathrm{p}}$, in the function of the normalised settlement, $\rho_{\mathrm{p}} / B_{\mathrm{p}}$, is reported in Figure 12 for tests on homogeneous sand bed and in Figure 13 for tests on sand bed with a weak layer.

The results plotted in Figures 12 and 13 show that the normalised applied pressure decreases as the stresses increase with the centrifuge acceleration $(a=N \boldsymbol{g})$, both in homogeneous soil and in the presence of the weak layer.

Figure 14 shows the bearing pressure $q$-normalised settlement $\rho_{\mathrm{m}} /$ $B_{\mathrm{m}}$ curves for $a=25 g(N=25)$ and an equivalent width of the prototype footing $40 \times 25 \mathrm{~mm}=1 \mathrm{~m}$ and for $a=40 \mathrm{~g}(N=40)$ corresponding to an equivalent prototype width of $1.60 \mathrm{~m}$. These curves show a rather small-scale effect in compliance with the modelling concepts. Figure 14 also shows that the curves, at the same $z_{i} / B$, are characterised by fairly comparable stiffnesses and that the stiffness in the presence of the weak layer is smaller than that for the homogeneous case (Figure 14(a)). Moreover, the stiffness increases with $z_{i} / B$ (Figures 14(b)-14(d)).

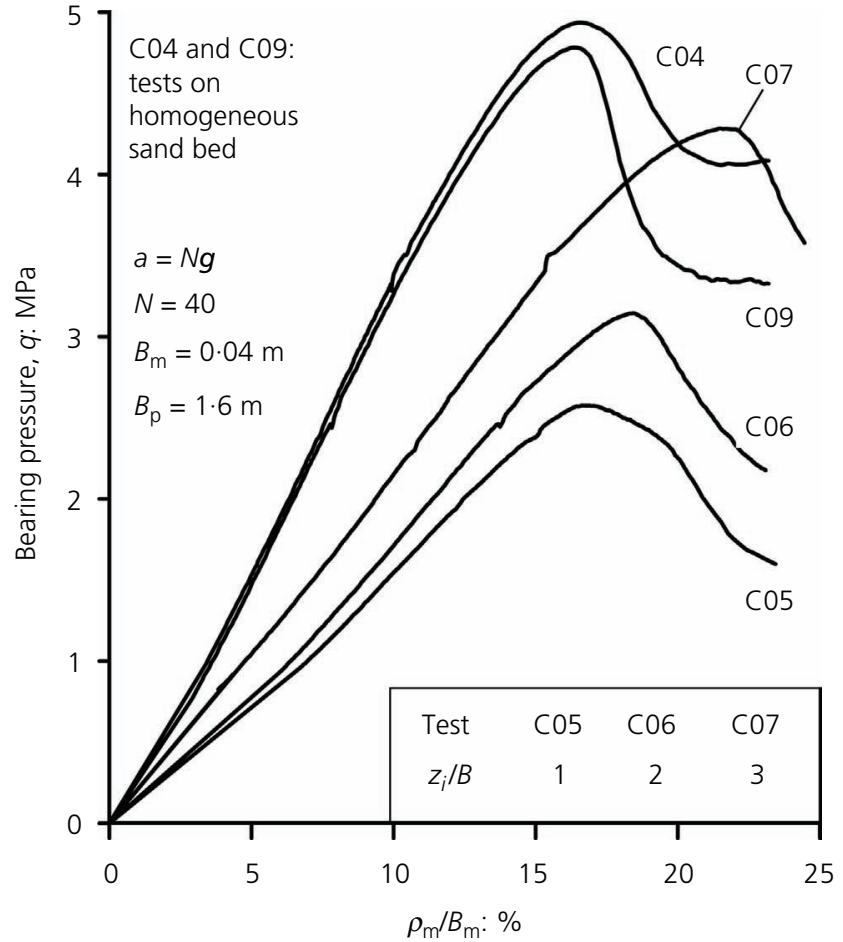

Figure 10. Bearing pressure-normalised settlement curves for tests performed at $a=40 \mathrm{~g}$. Results of tests C04 and C09 performed on homogeneous sand bed are reported for comparison. $B_{\mathrm{m}}=$ $40 \mathrm{~mm} ; B_{\mathrm{p}}=1.6 \mathrm{~m} . z_{i}$, depth of the weak layer. Weak layer made of $\mathrm{CM} 3$ talc powder

The ultimate bearing capacity, $q_{\text {lim }}$, has been normalised with respect to the ultimate bearing capacity, $q_{\lim , 0}$, relative to the case of the homogeneous sand bed. The values of $q_{\mathrm{lim}, 0}$ are $3870 \mathrm{kPa}$ for $N=25$ and $4937 \mathrm{kPa}$ for $N=40$. The ratio $q_{\mathrm{lim}} / q_{\mathrm{lim}, 0}$ is plotted against $z_{i} / B$ in Figure 15 . In this figure, the results relative to those of $1 \mathrm{~g}$ tests are also plotted for comparison. The minimum value of $q_{\lim } / q_{\lim , 0}$ is attained at $z_{i} / B=1$ with a reduction of the ultimate bearing capacity from 45 to $50 \%$ compared to the homogeneous sand case for tests at $25 \mathrm{~g}$ and $40 \mathrm{~g}$, respectively. For the singlegravity tests, this reduction is $46 \%$ and occurs at $z_{i} / B=1 . q_{\lim }$ tends to $q_{\lim , 0}$ at $z_{i} / B$ larger than 4 for both $1 \boldsymbol{g}$ and centrifuge tests.

The results presented earlier demonstrate the strong influence of the presence of a thin weak layer on the ultimate bearing capacity, $q_{\mathrm{lim}}$, which can undergo reductions as high as $48 \%$ relative to weak layers made of CM3 talc powder with $\phi_{2 p}^{\prime}=27^{\circ}$. Larger reductions are expected for $\phi_{2 \mathrm{p}}^{\prime}<27^{\circ}$. These results confirm those relative to tests performed at $a=1 \boldsymbol{g}$ on the same sand B $\left(d_{50}=0.45 \mathrm{~mm}\right)$ and on a coarser sand $\mathrm{A}\left(d_{50}=0.95 \mathrm{~mm}\right)$ (Valore et al., 2017).

\section{Scale effects}

It is well known that the ultimate bearing capacity reduces with increasing footing size and with increasing mean stress level (e.g. Bjerrum (1973), de Beer (1970), Shiraishi (1990), Briaud and 
Centrifuge tests on strip footings on sand

with a weak layer

Ziccarelli, Valore, Muscolino and Fioravante

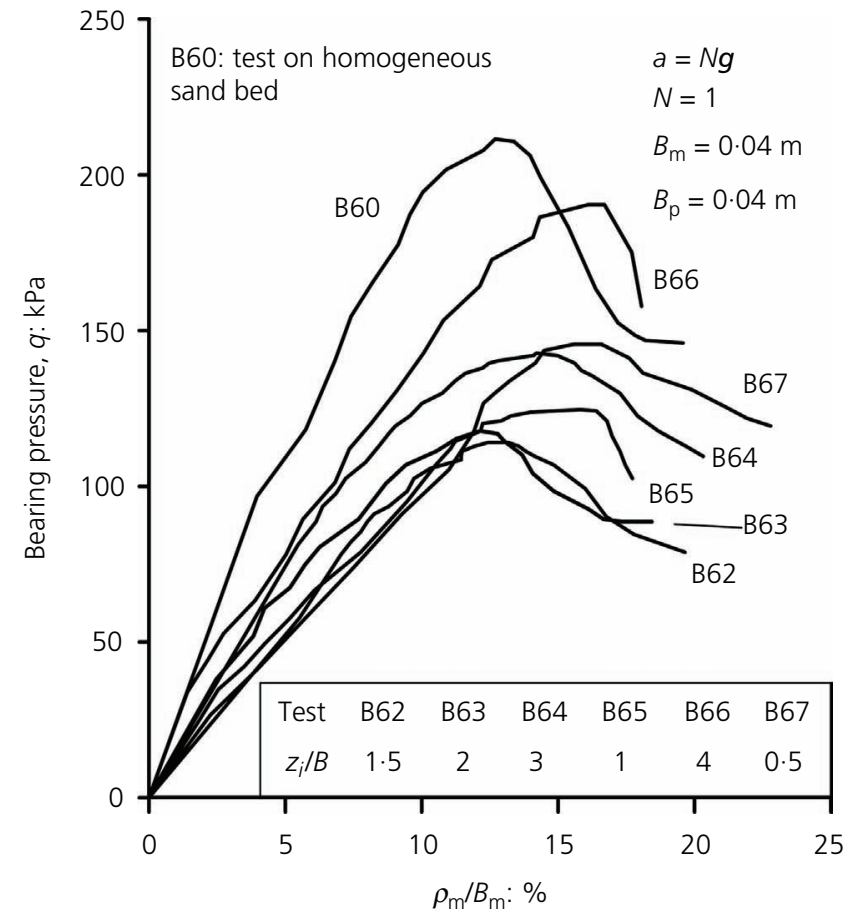

Figure 11. Bearing pressure-normalised settlement curves for tests at $\mathrm{a}=1 \mathrm{~g}$ on sand $\mathrm{B}$. Test B60, on homogeneous sand bed, shown for comparison. $B_{\mathrm{m}}=B_{\mathrm{p}}=0.04 \mathrm{~m}$. $z_{i}$, depth of the weak layer. Weak layer made of CM3 talc powder

Jeanjean (1994), Cerato and Lutenegger (2007), Kumar and Katri (2008), White et al. (2008), Chakraborty and Kumar (2016)).

The stress effects originate, first of all, from the marked curvature of the dense sand failure envelope that is particularly relevant at low stress. In small-scale physical models, the self-weight stresses are very or extremely low under 'normal-gravity' conditions; as a consequence, the angle of shearing resistance is higher and variable along the failure surface, contrary to what happens for real footings. Stress effects may also depend on the heterogeneity of the foundation soil and progressive failure. According to Muhs (1965), Hettler and Gudheus (1988) and Lau and Bolton (2011a), progressive failure may be considered marginal in small-scale model tests such as the present ones.

Figures 16 and 17 show the results of the model tests at different accelerations $(1 \mathrm{~g}, 25 \mathrm{~g}$ and $40 \mathrm{~g})$ on the same sand B (cp. Valore et al. (2017) for $1 g$ tests). In Figure 16(a), the trend of the 'equivalent ultimate bearing capacity factor' $N_{\gamma}^{*}=2 q_{\lim } /\left(\gamma B_{\mathrm{p}}\right)$ is plotted against the prototype width, $B_{\mathrm{p}}$, while in Figure 16(b), the experimental results relative to footing on homogeneous sand were compared with other experimental data (Kimura et al., 1985; Yamaguchi et al., 1976) and with some theoretical solution (Brinch Hansen, 1970; Kumar and Kouzer, 2007; Terzaghi, 1943; Vesić, 1973). In Figure 17, the ultimate bearing pressure, $q_{\mathrm{lim}}$, is plotted against $B_{\mathrm{p}}$.

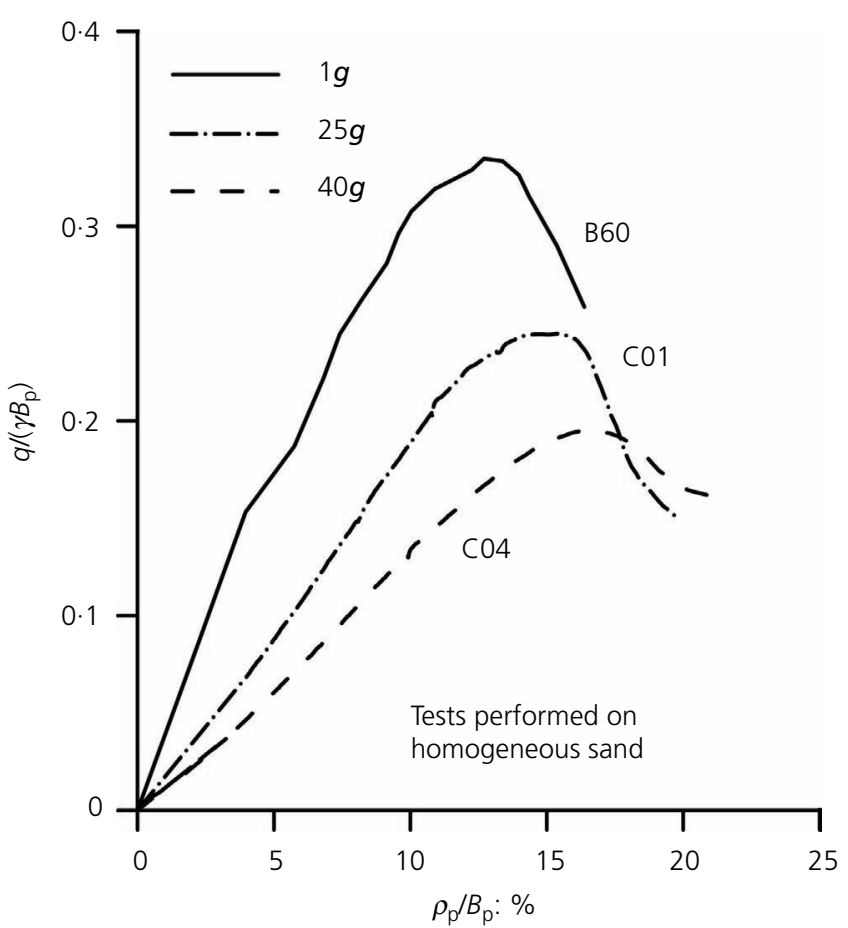

Figure 12. Tests on homogeneous sand. Normalised bearing pressure-normalised settlement curves at $1 g(N=1), 25 g(N=25)$ and $40 \mathrm{~g}(N=40)$

$N_{\gamma}^{*}$ for centrifuge tests was computed with reference to $\gamma_{\mathrm{d}}=$ $16 \cdot 1 \mathrm{kN} / \mathrm{m}^{3}$ (instead of $\gamma_{\mathrm{d}}=15.8 \mathrm{kN} / \mathrm{m}^{3}$ pertinent to single-gravity tests) in order to account for the densification undergone by the sand during the densification cycle phase.

The results shown in Figures 16 and 17 and in Figures 12 and 13 clearly confirm the well-known scale effects relative to homogeneous soils, observed both in single-gravity and in centrifuge tests (Kimura et al., 1985; Kutter et al., 1988; Tatsuoka et al., 1991; Ueno et al., 1998; Yamaguchi et al., 1977). They also demonstrate that the scale effects are present and are important for footings resting on sand bed in which a weak layer is present at depths smaller than a critical value, $z_{\text {crit }}$, depending on the ratio of its shear resistance angle $\left(\phi_{2 \mathrm{p}}^{\prime}\right)$ and that of the sand $\left(\phi_{1 \mathrm{p}}^{\prime}\right) . z_{\text {crit }}$ for the tested physical models ranges from $4 B_{\mathrm{m}}$ to $4 \cdot 5 B_{\mathrm{m}}$.

In all the analysed cases, for footings resting on either a homogeneous sand bed or one with a weak layer, at the same relative density of the sand, the general failure mechanisms are similar but the lateral extent of the failure surface in centrifuge tests is smaller than that in $1 \boldsymbol{g}$ tests. This is due to the fact that higher mean angles of shearing resistance operate in $1 \boldsymbol{g}$ tests.

\section{Back-analysis}

The main aims of the numerical analysis are to back-calculate the mobilised mean equivalent constant angle of shearing resistance, $\phi_{1 \mathrm{p}}^{\prime}$, of the sand (Lau and Bolton, 2011b) corresponding to the 
Centrifuge tests on strip footings on sand

with a weak layer

Ziccarelli, Valore, Muscolino and Fioravante

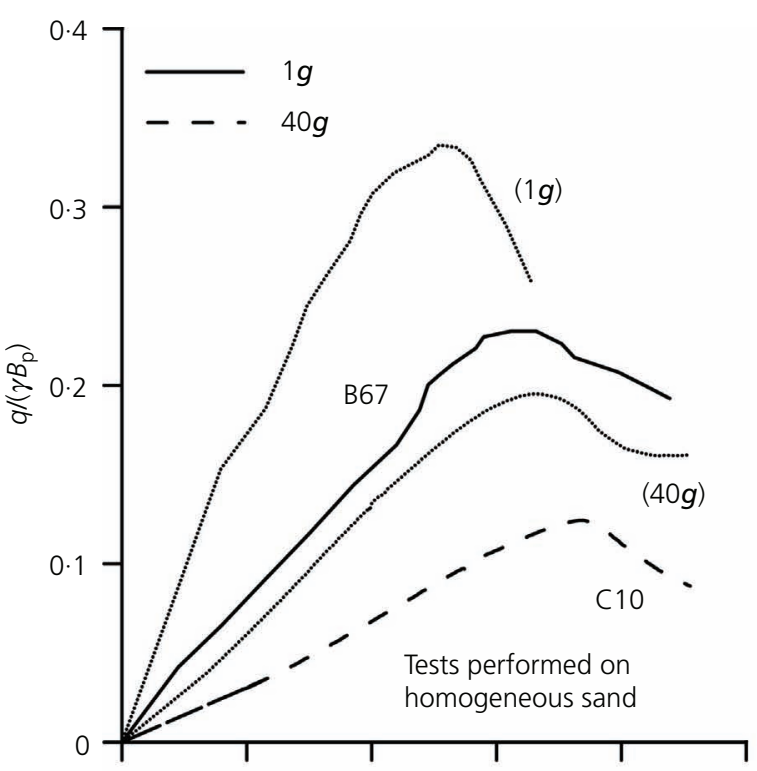

(a)

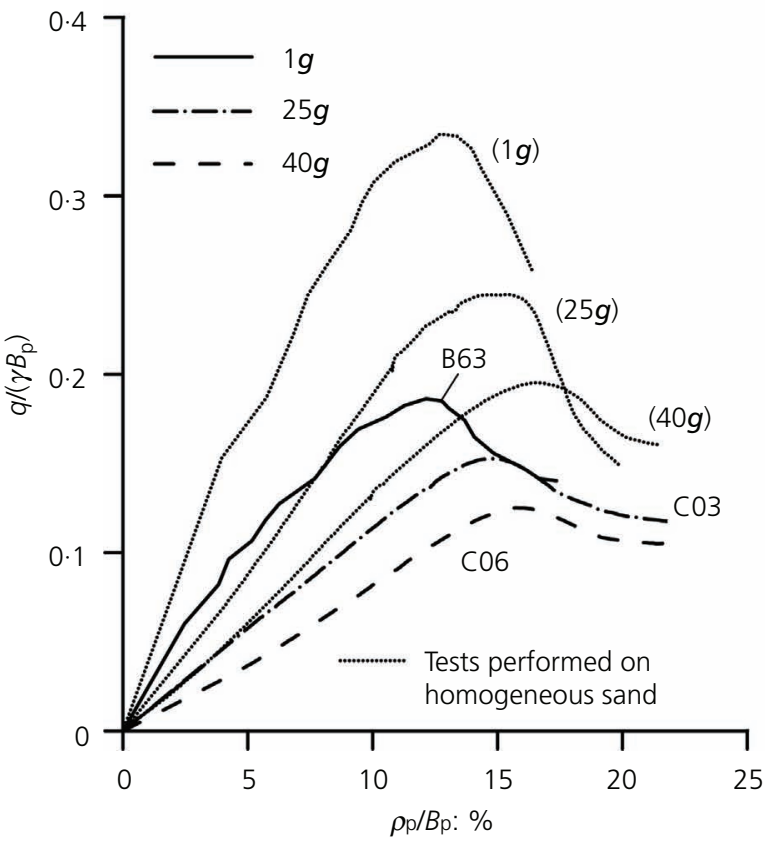

(c)

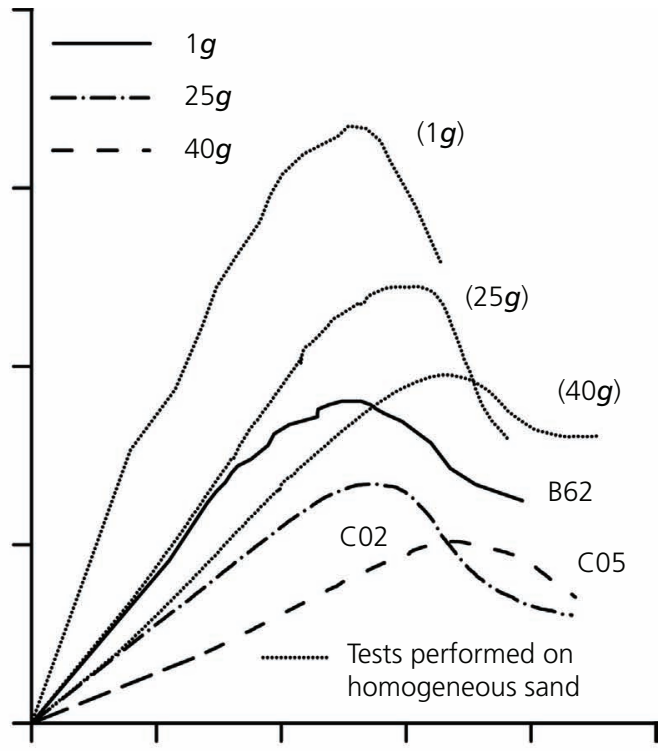

(b)

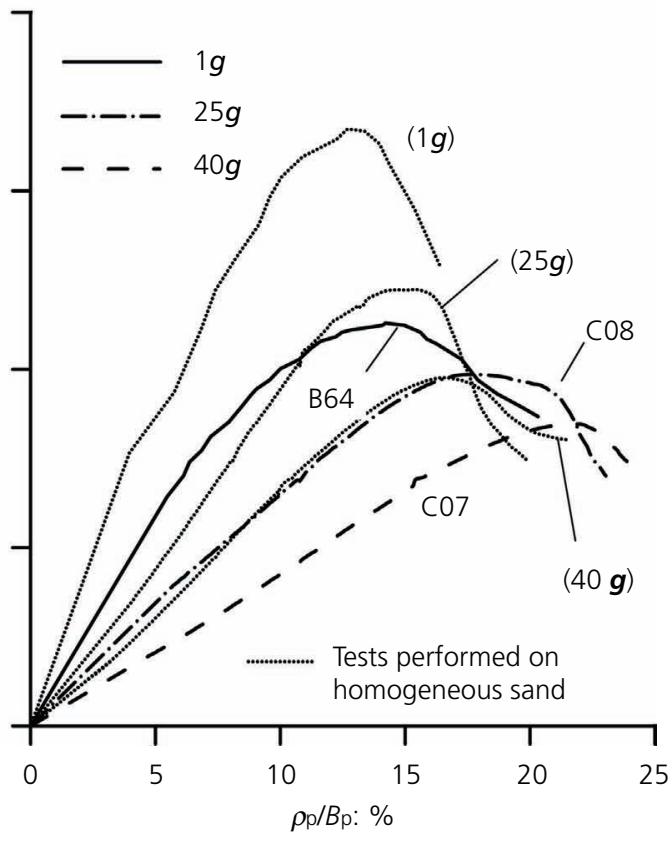

(d)

Figure 13. Normalised bearing pressure-normalised displacement curves in the function of the ratio $z_{i} / B$ for tests at $1 g(N=1), 25 g(N=$ 25) and $40 \mathrm{~g}(N=40):(a) z_{i} / B=0 \cdot 5,(\mathrm{~b}) z_{i} / B=1$, (c) $z_{i} / B=2$ and (d) $z_{i} / B=3$. Dotted lines refer to tests carried out on homogeneous sand and are plotted for comparison

ultimate bearing pressure, $q_{\mathrm{lim}}$, and to compare the features of the computed failure mechanisms against the experimental ones.

The reference scheme for the finite-element (FE) analysis is shown in Figure 18 along with the boundary conditions. Plane strain state and drained conditions are assumed. To avoid meshrelated dissymmetries, only the half model is analysed. The unit weight of the materials and the angle of shearing resistance of the weak layer are assumed to be known. The cohesion intercept is always considered nil. The numerical simulations are carried out using the FE code Plaxis 2D (Plaxis, 2008), considering the geometry of the reduced-scale physical model of the soil-footing system for single-gravity as well as for centrifuge tests. The unit weight of soils has been set equal to $\gamma=N \boldsymbol{g} \rho^{*}(N=1,25$ or 40 , $\rho^{*}$ being the density). The footing is subjected to a vertical load, $Q$, corresponding to an average bearing pressure, $q$, on the 


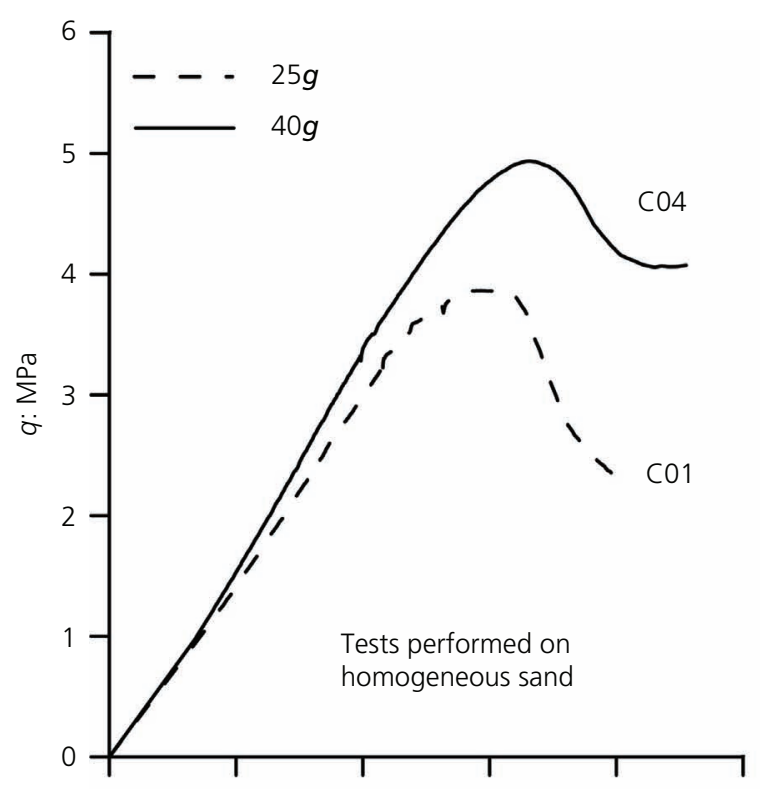

(a)

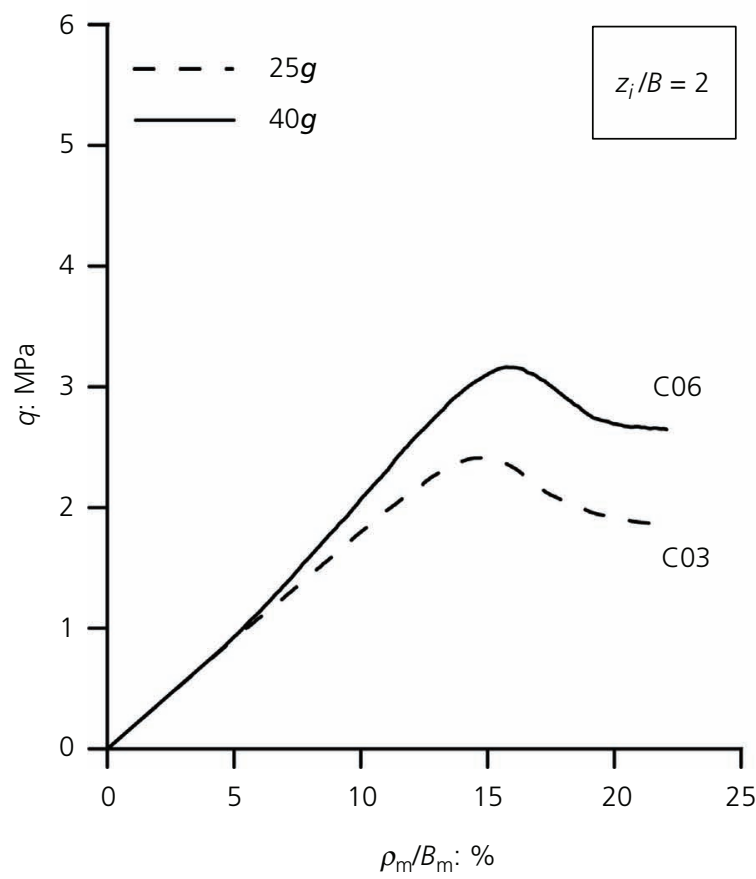

(c)

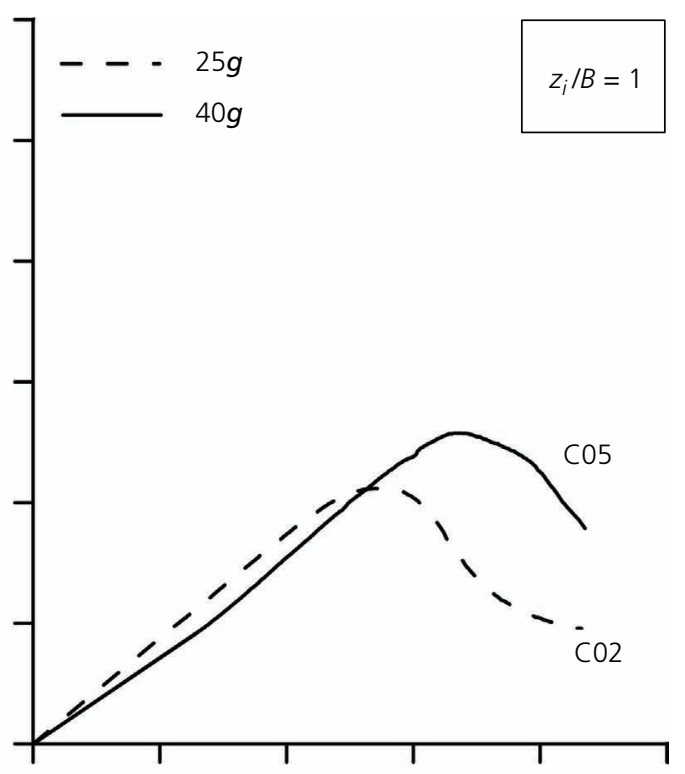

(b)

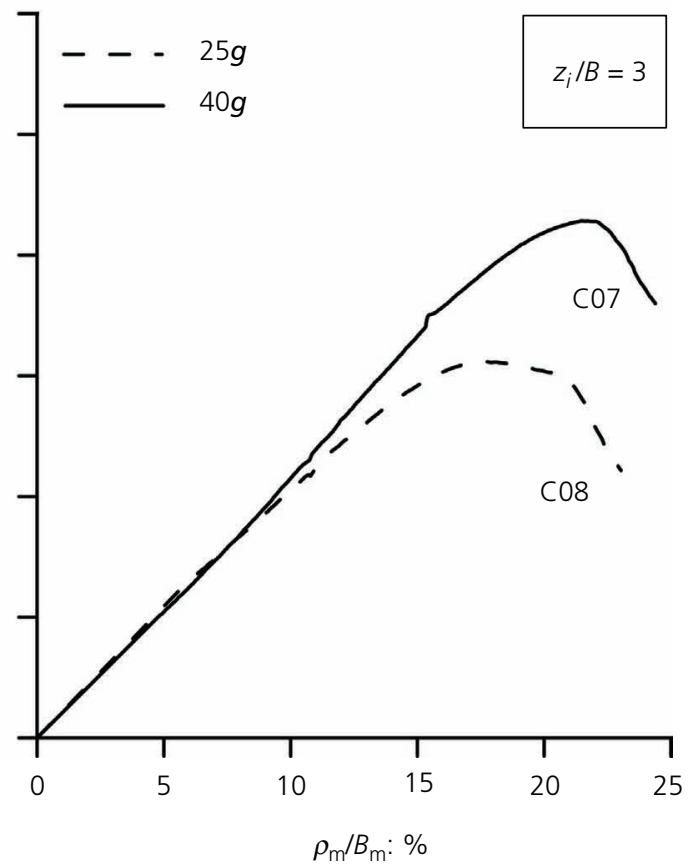

(d)

Figure 14. Bearing pressure-normalised settlement curves as a function of the ratio $z_{i} / B$ for tests at $25 g(N=25)$ and $40 g(N=40)$. Tests $\mathrm{CO} 1$ and C04 performed on homogeneous sand. At $25 \mathrm{~g}$ and $40 \mathrm{~g}$, the equivalent prototype footing widths $B_{\mathrm{p}}$ are 1 and $1.6 \mathrm{~m}$, respectively

soil-footing interface. Actually, a uniform vertical settlement of the footing base is imposed rather than the vertical load, $Q$, so duplicating the true experimental procedure and accounting for the high stiffness of the footing and for the roughness of its base (Lee et al., 2013). The simple elastic-perfectly plastic Mohr-Coulomb constitutive model with non-associated flow rule is used for soils as many other authors have (e.g. Bolton and Lau (1993), Yin et al. (2001), Potts (2003), Mabrouki et al. (2010),
Kumar and Khatri (2011)). Geometric variations of the system and their effects on the stress state in the soil are not taken into account. This hypothesis and the assumption of perfect plasticity imply that pre-peak hardening, post-peak strain softening and the dependence of angle of shearing resistance, $\phi_{1 \mathrm{p}}^{\prime}$, on stress level variations within the relevant soil volume are not taken into account, although there are more sophisticated constitutive models available that allow modelling of the post-peak behaviour 
Centrifuge tests on strip footings on sand

with a weak layer

Ziccarelli, Valore, Muscolino and Fioravante

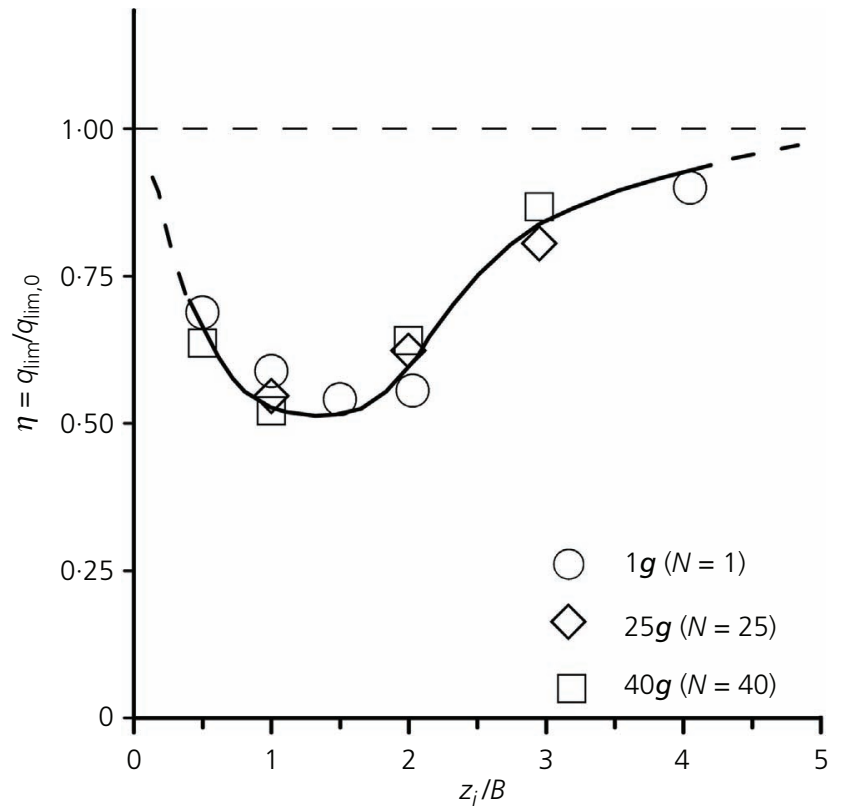

Figure 15 . Normalised ultimate bearing capacity $q_{\text {lim }} / q_{\text {lim,o }}$ against normalised depth $z_{i} / B$ for different values of $N=a / g$ of the weak layer. $q_{\text {lim, }, 0}$, ultimate bearing capacity of the footing on homogeneous sand. $B_{\mathrm{m}}=40 \mathrm{~mm}$, footing width; $z_{i}$, depth of the weak layer. Data relative to $1 g$ tests (sand B) reported for comparison. Weak layers made of CM3 talc powder with $\phi_{2 p}^{\prime}=27^{\circ}$ of the soil-footing system (e.g. Potts and Zdravkovic (1999), Yin et al. (2001), Potts (2003), Siddiquee et al. (1999, 2001), Cassidy et al. (2002), Salgado (2008), Loukidis and Salgado (2009, 2011)). An equivalent constant mean value of $\phi_{1 \mathbf{p}}^{\prime *}$ has been sought (Lau and Bolton, 2011b; Lee et al., 2013). Of course, under $1 \mathrm{~g}$ conditions, the shear strength parameters in the low-stress range strongly depend on the effective stress level; consequently, they vary, within the relevant soil volume, from 'lower' values in the zone beneath the footing (where the effective normal stresses are relatively large) to higher values within the passive zone, where the stresses in tested $1 \boldsymbol{g}$ physical models are low or extremely low (Lau and Bolton, 2011a, 2011b). In contrast, in the case of centrifuge tests at $25 \mathrm{~g}$ or $40 \mathrm{~g}$, the average stress intensity within the relevant soil volume is high enough so that only modest variations in $\phi_{1 \mathrm{p}}^{\prime *}$ occur along the failure mechanism.

The dilatancy angle was always related to the peak shear strength, $\phi_{1 \mathrm{p}}^{\prime *}$, by Bolton's relation $\psi_{1 \mathrm{p}}^{* *}=1 \cdot 25\left(\phi_{1 \mathrm{p}}^{\prime *}-\phi_{1 \mathrm{cv}}^{\prime}\right)$ (Bolton, 1986), in which $\phi_{1 \mathrm{cv}}^{\prime}=32^{\circ}$. Progressive failure is not taken into account as suggested by the results in $1 \boldsymbol{g}$ small- and large-scale physical models and in centrifuge tests carried out by Muhs (1965), Hettler and Gudheus (1988) and Lau and Bolton (2011a). The preceding hypotheses do not permit the prediction of the behaviour of the soil-footing system beyond the peak bearing pressure (Potts and Zdravkovic, 1999, 2001).

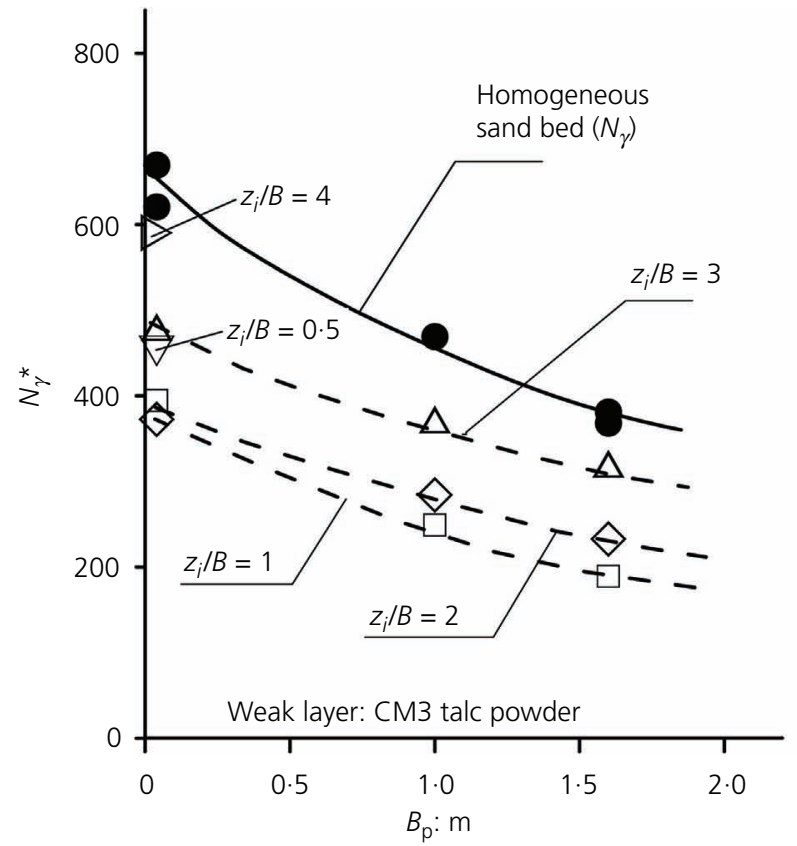

(a)

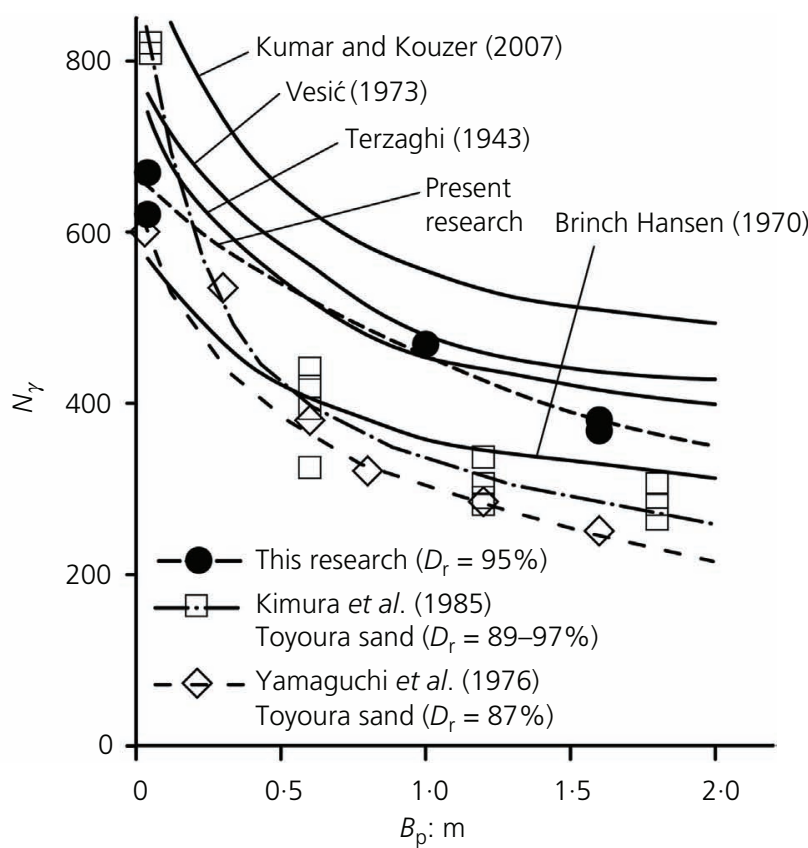

(b)

Figure 16. Strip footing on sand B with or without a weak layer at depth $z_{i}$. Weak layer made of CM3 talc powder. (a) Equivalent ultimate bearing capacity factor $N_{\gamma}^{*}=2 q_{\lim } /\left(\gamma_{\mathrm{d}} B_{\mathrm{p}}\right)$ against $B_{\mathrm{p}}$ equivalent prototype width. (b) $N_{\gamma}$ for strip footing on homogeneous sand. Comparison of results of the present research with other experimental data and with theoretical solutions for $\phi_{1 \mathrm{p}}^{\prime}$ values according to Figure 3(c) 


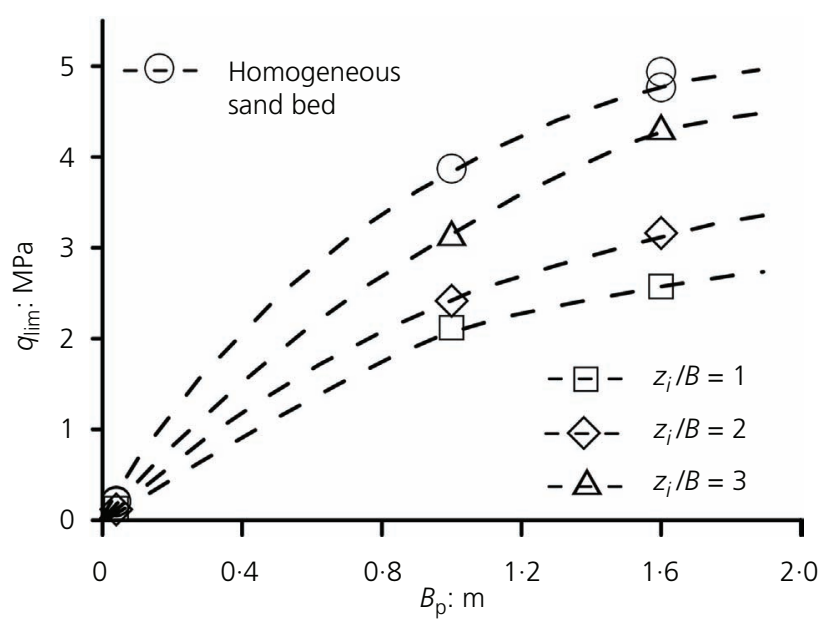

Figure 17. Ultimate bearing capacity $q_{\lim }$ against prototype width $B_{\mathrm{p}} . z_{i}$, depth of the weak layer made of CM3 talc powder

\section{Homogeneous sand bed}

First, the homogeneous sand bed-footing systems were backanalysed. A good match of experimental and calculated results was reached as far as the ultimate bearing pressure, $q_{\mathrm{lim}, 0}$, the bearing pressure-settlement curve (up to $q_{\lim , 0}$ ) and the failure mechanisms are concerned.

The following parameters have been considered for the sand: Young's modulus: $E^{\prime}=125 \mathrm{MPa}$, Poisson's ratio $v^{\prime}=0.15$ and coefficient of Earth pressure at rest $K_{0}=0 \cdot 4$. Results of the back-analysis for tests performed at acceleration $a=40 \boldsymbol{g}(N=40)$ are shown in Figures 19 and 20. The failure mechanism (Figure 19) closely resembles Prandtl's (1920) except for the angle of emersion at ground surface that nearly equals $45^{\circ}-\psi_{1 \mathrm{p}}^{\prime} / 2$ (instead of $45^{\circ}-\phi_{1 \mathrm{p}}^{\prime} / 2$ ). The small instability of numerical results in the pre-peak phase is due to the non-associativity of the constitutive model (Frydman and Burd, 1997).

The values of the equivalent mean angle of mobilised shear strength are $\phi_{1 \mathrm{p}}^{\prime *}=47 \cdot 8^{\circ}\left(\psi_{1 \mathrm{p}}^{\prime *}=19 \cdot 5^{\circ}\right)$ for tests at $25 g(N=25)$ and $\phi_{1 \mathrm{p}}^{\prime *}=47 \cdot 6^{\circ}\left(\psi_{1 \mathrm{p}}^{\prime *}=19 \cdot 7^{\circ}\right)$ for tests at $40 \mathrm{~g}(N=40)$.

The calculated values of $\phi_{1 \mathrm{p}}^{*}$ are in good agreement with the experimental results of direct shear tests (Figure 3) pertaining to the range of normal stress from 250 to $350 \mathrm{kPa}$. This range has been selected according to Meyerhof (1951), who suggested that the value of the mean normal stress, $\sigma_{0}^{\prime}$, along the failure surface is about $1 / 10$ of the ultimate bearing capacity, $q_{\text {lim }}$, and according to de Beer (1965), who proposed the following relation: $\sigma_{0}^{\prime}=$ $0 \cdot 25 q_{\lim }\left(1-\sin \phi_{1 \mathrm{p}}^{\prime}\right)$.

\section{Sand bed with weak layer}

Despite its simplifications, the numerical analysis allows accurate identification of the failure mechanisms that match the experimental ones quite well, as shown, for example, by Figures 21-23, which are to be compared to the results of centrifuge tests at $40 \mathrm{~g}: \mathrm{C} 10, \mathrm{C} 05$ and $\mathrm{C} 06$. For the sake of simplicity of the numerical simulation, the values of Young's modulus, Poisson's ratio and the dry unit weight, $\gamma_{\mathrm{d} 2}$, of the weak layer were assumed equal to those of the sand. The calculations were performed assuming, always (i.e. irrespectively of the depth of the weak layer), for sand $\phi_{1 \mathrm{p}}^{\prime}=47 \cdot 6^{\circ}$ obtained from the back-analysis of test $\mathrm{C} 04$ at $40 \mathrm{~g}$ on homogeneous sand bed. The numerical analyses confirm that when the weak layer is located at depth $z_{i}=0 \cdot 5 B$, the failure mechanism crosses the weak layer, develops through a radial shear zone within the underlying sand and runs upwards along an inclined plane inclined $45^{\circ}$ (Figure 6(a)), which crosses the weak layer again before emerging onto the ground

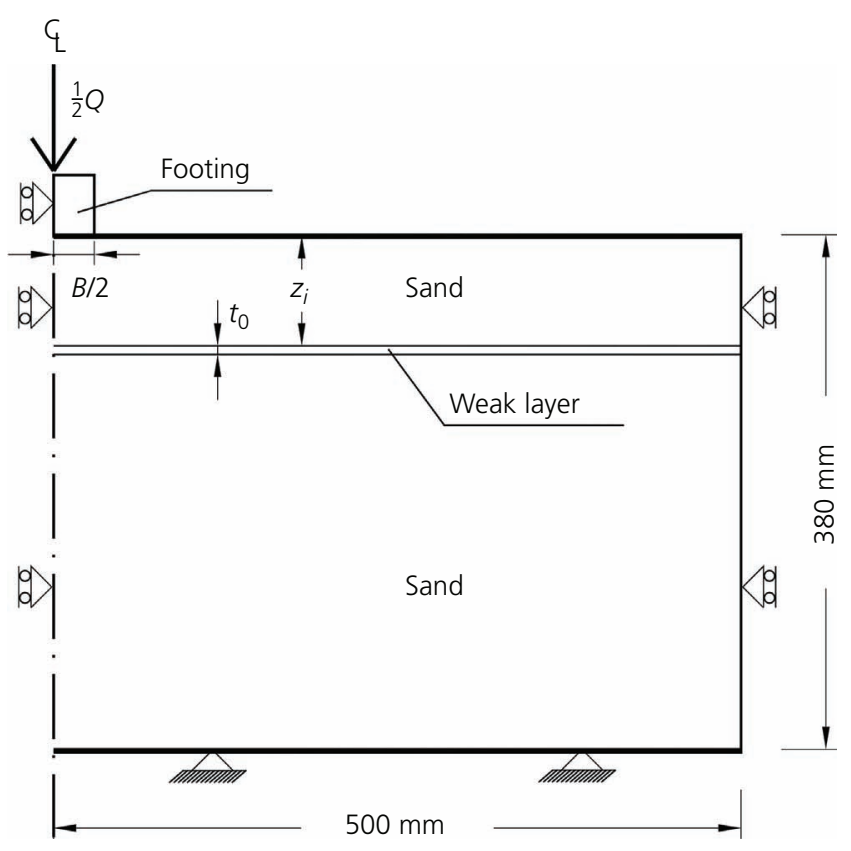

Figure 18. Reference scheme for FE analysis. Unit weight of soil $\gamma=N g \rho^{*}(N=1,25$ or 40$)$. $Q$, vertical load or resultant of the pressures transmitted to the soil by the footing

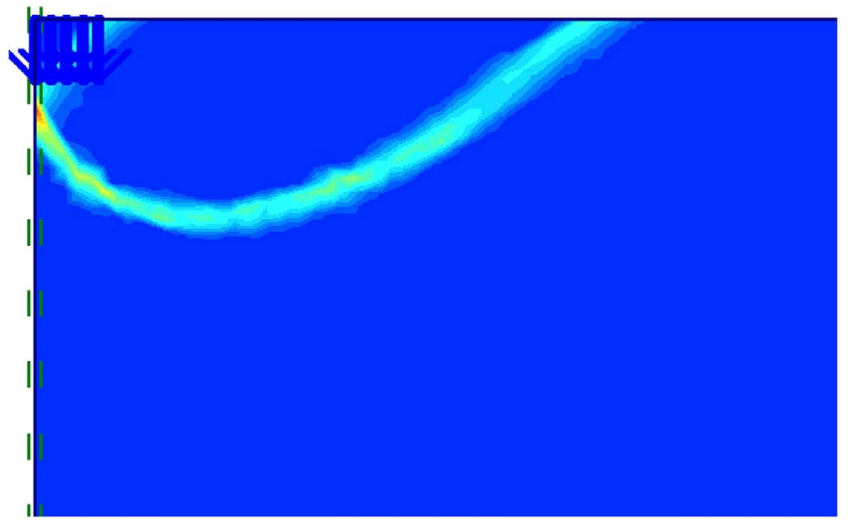

Figure 19. Footing on homogeneous sand bed, $N=40$. Incremental shear strains at failure. Compare with test C04 
Centrifuge tests on strip footings on sand

with a weak layer

Ziccarelli, Valore, Muscolino and Fioravante

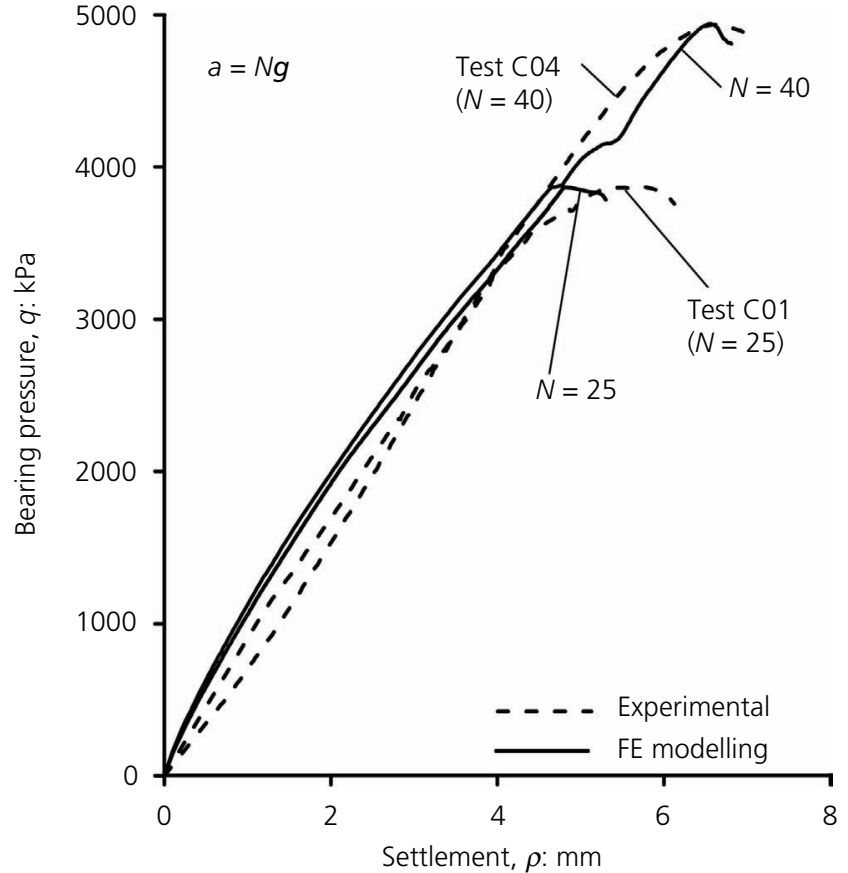

Figure 20. Footing on homogeneous sand bed. Comparison between numerical and experimental load-settlement curves (test C04, $N=40$; test C01, $N=25$ )

surface. In the cases shown in Figures 22 and 23, the failure mechanisms found by the numerical analysis develop in part along the weak layer similarly to experimental results.

The values of $q_{\lim } / q_{\lim , 0}$ calculated by using the equivalent constant strength parameters of the sand back-calculated for the homogeneous case for $N=25$ and $N=40$ are plotted in Figures 24 and 25 , respectively.

It can be observed that the results of numerical analysis match the experimental data very well. These figures prove that at enhanced

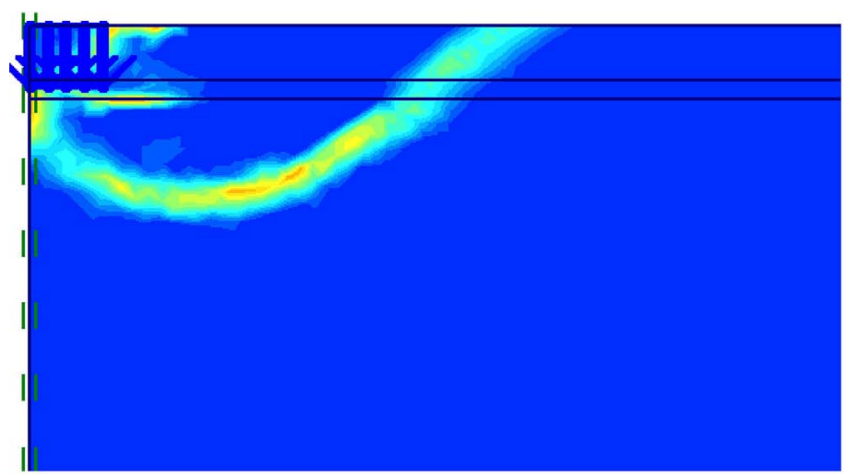

Figure 21. Incremental shear strains at failure for $z_{i} / B=0 \cdot 5$. Weak layer made of $\mathrm{CM} 3$ talc powder. Compare with test $\mathrm{C} 10$ (Figure $6(\mathrm{a})$ ). $N=40$

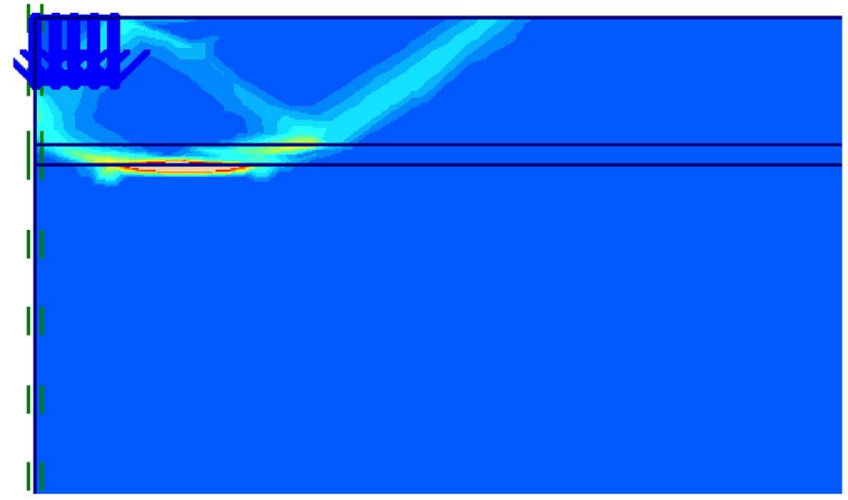

Figure 22. Incremental shear strains at failure for $z_{i} / B=1$. Weak layer made of CM3 talc powder. Compare with test C05 (Figure $6(\mathrm{~b})) . \quad N=40$

gravity, the mean equivalent angle of shearing strength, $\phi_{1 \mathrm{p}}^{\prime *}$, is not appreciably affected by the stress-related variability of $\phi_{1 \mathrm{p}}^{\prime}$ and by the depth of the weak layer, in contrast with what occurs for $1 \mathrm{~g}$ tests (Valore et al., 2017). The earlier-mentioned figures also confirm the remarkable effect of the presence of the weak layer on the ultimate bearing capacity, which may undergo reductions as high as $50 \%$ when the weak layer is made of $\mathrm{CM} 3$ talc powder with a shearing resistance angle, $\phi_{2 \mathrm{p}}^{\prime}$, equal to $27^{\circ}$. For this latter value of $\phi_{2 \mathrm{p}}^{\prime}$, the experimental results along with the experimental ones clearly suggest that the critical adimensionalised depth $z_{i} / B$ closely approaches 4 .

\section{Conclusions}

The influence of a horizontal thin weak soil layer interposed in a dense sand bed on the behaviour of a shallow strip footing loaded to failure was investigated by means of centrifuge tests on smallscale physical models. From the test results, the following conclusions can be drawn.

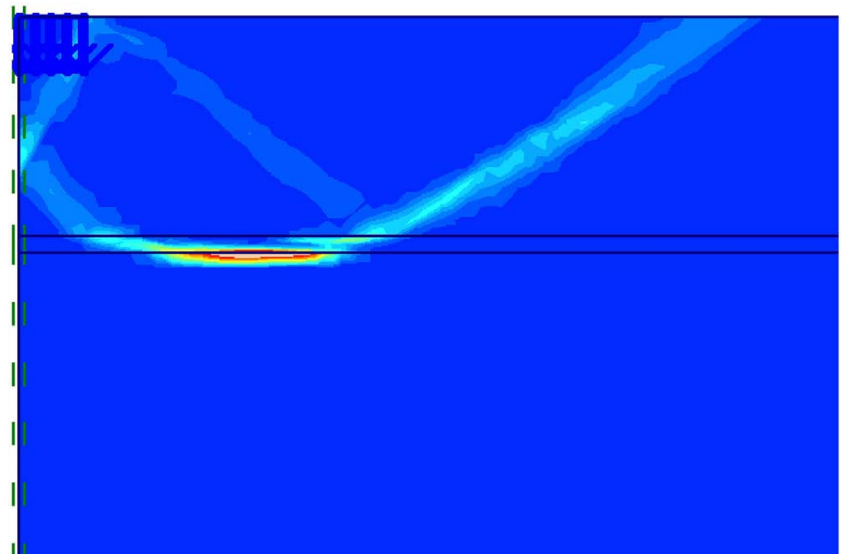

Figure 23. Incremental shear strains at failure for $z_{i} / B=2$. Weak layer made of CM3 talc powder. Compare with test C06 (Figure 6(c)). $N=40$ 
Centrifuge tests on strip footings on sand

with a weak layer

Ziccarelli, Valore, Muscolino and Fioravante

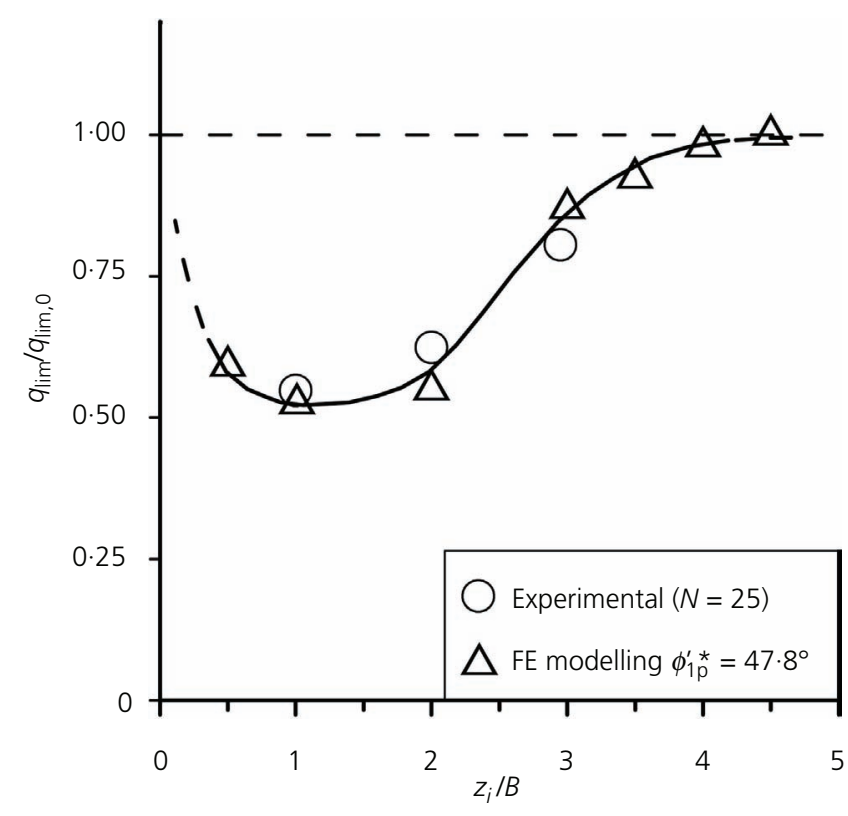

Figure 24. Results of back-calculations. Comparison between numerical and experimental values of $q_{\mathrm{lim}} / q_{\mathrm{lim}, 0}$ against $z_{i} / B$ for $N=25$. Weak layer made of CM3 talc powder

The weak layer strongly influences both the failure mechanism and the ultimate bearing capacity, $q_{\text {lim }}$, if its depth, $z_{i}$, does not exceed a critical value of about $4 B$ for the tested materials (sand and talc powder making up the weak layer). In general, this critical value

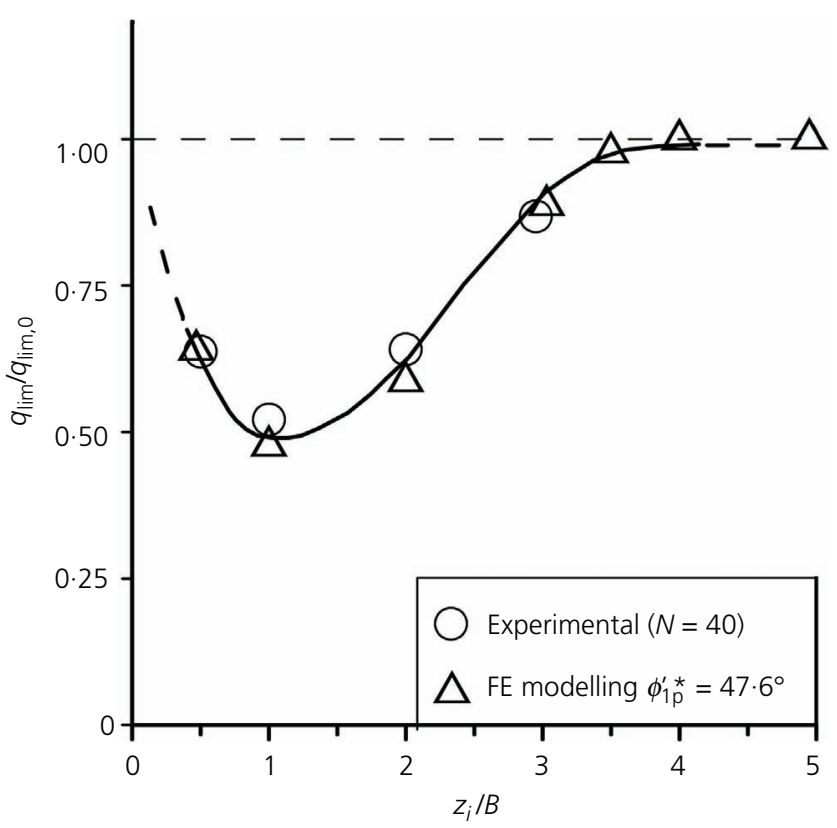

Figure 25. Results of back-calculations. Comparison between numerical and experimental values of $q_{\lim } / q_{\lim , 0}$ against $z_{j} / B$ for $N=40$. Weak layer made of CM3 talc powder varies as a function of the ratio $\phi_{1 \mathrm{p}}^{\prime} / \phi_{2 \mathrm{p}}^{\prime}$ between the angles of shearing resistance of the sand and the material making up the weak layer. The failure surface cuts through the weak layer when the latter is located at small depths, $z_{i}$, beneath the footing $\left(z_{i} / B \leq 0.5\right)$; at larger depths $\left(0.5 \leq z_{i} / B \leq 3\right)$, the weak layer controls the maximum depth of the mechanism, forcing it to run partly horizontally along the weak layer before going up through the upper sand layer.

The ultimate bearing capacity, $q_{\lim }$, is always lower than $q_{\lim , 0}$ pertinent to the homogeneous sand bed. The experiments show a reduction in $q_{\lim }$ of up to $50 \%$ for weak layers made of talc powder with an angle of shearing resistance of $27^{\circ}$; larger reductions are expected for smaller values of $\phi_{2 \mathrm{p}}^{\prime}$.

The presence of a weak layer reduces the stiffness of the load-settlement curve before $q_{\text {lim }}$ is reached. Numerical simulations of the reduced-scale centrifuge physical model tests by FE analysis are able to capture the failure mechanisms and the ultimate bearing capacity correctly, even if the very simple constitutive Mohr-Coulomb model is used. Moreover, they point out that the equivalent mean constant value of the sand angle of shearing resistance in tests at enhanced gravity is little influenced by the location and the properties of the weak layer, in contrast with what happens for single-gravity tests.

The test results confirm those relative to single-gravity tests, reported in a companion paper (Valore et al., 2017), also carried out on a coarser sand and using materials for the weak layer with a wide range of angles of shearing resistance.

Scale effects, well known for homogeneous sands, also operate in sand beds containing a thin horizontal weak layer.

Bearing capacity factors, $N_{\gamma}$, derived from results of tests on footing on homogeneous sand bed decrease with the prototype width and are in good agreement with other published experimental results and with theoretical solutions by Brinch Hansen (1970), Terzaghi (1943) and Vesić (1973). An equivalent bearing capacity factor, $N_{\gamma}^{*}$, has been derived for a sand bed containing a thin weak layer; it is lower than $N_{\gamma}$ and depends on the location and shearing resistance of the weak layer.

The results of tests carried out at different accelerations and of the back-analysis encourage confident numerical predictions of the behaviour of actual soil-footing systems of the kind dealt with in the paper.

\section{Acknowledgements}

This research was partly supported by the Ministry of Education, Universities and Research (Progetti di Rilevante Interesse Nazionale (Prin): Gallerie in 'sezione mista', Project 9908328717_009). This support is gratefully acknowledged. The authors wish to thank the laboratory technicians Dr Eng. A. Casella and Dr Geol. G. Sapienza of the geotechnical laboratory of the University of Palermo and the technicians of the ISMGeo for their assistance during the tests. 


\section{REFERENCES}

Aiban SA and Znidarčić D (1995) Centrifuge modeling of bearing capacity of shallow foundations on sand. Journal of Geotechnical Engineering 121(10): 704-712, http://dx.doi.org/10.1061/(ASCE)0733-9410(1995) $121: 10(704)$

Altaee A and Fellenius BH (1994) Physical modeling in sand. Canadian Geotechnical Journal 31(3): 420-431, http://dx.doi.org/10.1139/t94049

ASTM (2004a) D 4253-00: Standard test methods for maximum index density and unit weight of soils using a vibratory table. ASTM International, West Conshohocken, PA, USA.

ASTM (2004b) D 4254-00: Standard test methods for minimum index density and unit weight of soils and calculation of relative density. ASTM International, West Conshohocken, PA, USA.

Baldi G, Belloni G and Maggioni W (1988) The ISMES centrifuge. In Proceedings of International Conference on Geotechnical Centrifuge Modelling, Centrifuge '88, Paris (Corté JF (ed.)). Balkema, Rotterdam, the Netherlands, pp. 45-48.

Bjerrum L (1973) Geotechnical problems involved in foundations of structures in the North Sea. Géotechnique 23(3): 319-358, http://dx. doi.org/10.1680/geot.1973.23.3.319.

Bolton MD (1986) The strength and dilatancy of sands. Géotechnique 36(1): 65-78, http://dx.doi.org/10.1680/geot.1986.36.1.65.

Bolton MD and Lau CK (1989) Scale effects in the bearing capacity of granular soils. Proceedings of the 12th International Conference on Soil Mechanics and Foundation Engineering, Rio de Janeiro, Brazil, vol. 2, pp. 895-898.

Bolton MD and Lau CK (1993) Vertical bearing capacity factors for circular and strip footings on Mohr-Coulomb soil. Canadian Geotechnical Journal 30(6): 1024-1033, http://dx.doi.org/10.1139/t93099.

Briaud JL and Jeanjean P (1994) Load-settlement curve method for spread footings on sand. In Vertical and Horizontal Deformations of Foundations and Embankments 1994 (Yeung AT and Félio GY (eds)). American Society of Civil Engineers, Reston, VA, USA, Special Publication No. 40, vol. 2, pp. 1774-1804.

Brinch Hansen J (1970) A revised extended formula for bearing capacity. Danish Geotechnical Institute Bulletin 28: 5-11.

Cassidy MJ, Byrne BW and Houlsby GT (2002) Modelling the behaviour of circular footings under combined loading on loose carbonate sand. Géotechnique 52(10): 705-712, http://dx.doi.org/10.1680/geot.2002. 52.10 .705 .

Cerato $A B$ and Lutenegger AJ (2007) Scale effects of shallow foundation bearing capacity on granular material. Journal of Geotechnical and Geoenvironmental Engineering 133(10): 1192-1202, http://dx.doi.org/ 10.1061/(ASCE)1090-0241(2007)133:10(1192).

Chakraborty M and Kumar J (2016) The size effect of a conical footing on $N_{\gamma}$. Computers and Geotechnics 76: 212-221, http://dx.doi.org/10. 1016/j.compgeo.2016.03.010.

de Beer EE (1965) The scale effect on the phenomenon of progressive rupture in cohesionless soils. Proceedings of the 6th ICSMFE Montreal, QC, Canada, vol. 2, pp. 13-17.

de Beer EE (1970) Experimental determination of the shape factors and bearing capacity factors of sand. Géotechnique 20(4): 387-411, http:// dx.doi.org/10.1680/geot.1970.20.4.387.

Dijkstra J, White DJ and Gaudin C (2013) Comparison of failure modes below footings on carbonate and silica sands. International Journal of Physical Modelling in Geotechnics 13(1): 1-12, http://dx.doi.org/10. 1680/ijpmg.12.00004.

Fioravante V (1999) Sui principî della modellazione fisica con particolare riferimento alla centrifuga geotecnica. Università della Calabria, Rende, Italy (in Italian).

Fioravante V (2002) On the shaft friction modelling of non-displacement piles in sand. Soils and Foundations 42(2): 23-33, http://doi.org/10. 3208/sandf.42.2_23.
Fioravante V, Ghiretti D, Prearo C and Lai C (2012) Static and dynamic centrifuge modeling landslide stabilization with large-diameter shafts. Soils and Foundations 42(2): 23-33.

Frydman S and Burd HJ (1997) Numerical studies of the bearing capacity factor $N_{\gamma}$. Journal of Geotechnical Engineering 123(1): 20-29, http:// dx.doi.org/10.1061/(ASCE)1090-0241(1997)123:1(20).

Garnier J and König D (1998) Scale effects in piles and nails loading tests in sand. In Proceedings of the International Conference Centrifuge '98, Tokyo (Kimura T, Kusakabe O and Takemura J (eds)). Balkema, Rotterdam, the Netherlands, vol. 1, pp. 205-210.

Gemperline MC and Ko HY (1984) Centrifugal model tests for ultimate bearing capacity of footings on steep slopes in cohesionless soils. In Proceedings of Application of Centrifuge Modelling to Geotechnical Design, Manchester, UK (Craig W (ed.)). Balkema, Rotterdam, the Netherlands, pp. 206-225.

Hansen B and Christensen NH (1969) Discussion on 'Theoretical bearing capacity of very shallow footings' by Larkins AL. Journal of Soil Mechanics and Foundation Division 95(SM6): 1568-1573.

Herle I and Tejchman J (1997) Effects of grain size and pressure level on bearing capacity of footings on sand. In Deformation and Progressive Failure in Geomechanics, IS-Nagoya '97 (Asaoka A, Adachi T and Oka F (eds)). Pergamon, Elsevier Science Ltd, Oxford, UK, pp. 781-786.

Hettler A and Gudheus G (1988) Influence of the foundation width on the bearing capacity factor. Soils and Foundations 28(4): 81-92, http:// doi.org/10.3208/sandf1972.28.4 81.

Kimura T, Kusakabe O and Saitoh K (1985) Geotechnical model tests of bearing capacity problems in a centrifuge. Géotechnique 35(1): 33-45, http://dx.doi.org/10.1680/geot.1985.35.1.33.

Kishida $\mathrm{H}$ and Useugi M (1987) Tests of the interface between sand and steel in the simple shear apparatus. Géotechnique 37(1): 45-52, http:// dx.doi.org/10.1680/geot.1987.37.1.45.

Kumar J and Kouzer KM (2007) Effect of footing roughness on bearing capacity factor $N_{\gamma}$. Journal of Geotechnical and Geoenvironmental Engineering 133(5): 502-511, http://dx.doi.org/10.1061/(ASCE)10900241(2007)133:5(502).

Kumar J and Khatri VN (2008) Effect of footing width on $N_{\gamma}$. Canadian Geotechnical Journal 45(12): 1673-1684, http://dx.doi.org/10.1139/ T08-113.

Kumar J and Khatri VN (2011) Bearing capacity factors of circular foundations for a general $c-\phi$ soil using lower bound finite elements limit analysis. International Journal for Numerical and Analytical Method in Geomechanics 35(3): 393-405, http://dx.doi.org/10.1002/ nag.900.

Kusakabe O (1992) Large-scale loading tests of shallow footings in pneumatic caissons. Journal of Geotechnical Engineering ASCE 118(11): 1681-1695, http://dx.doi.org/10.1061/(ASCE)0733-9410 (1992)118:11(1681).

Kusakabe O (1995) Foundations. In Geotechnical Centrifuge Technology (Taylor RN (ed.)). Blackie Academic \& Professional, London, UK, pp. $118-167$.

Kusakabe O, Yamaguchi H and Morikage A (1991) Experiment and analysis on the scale effect of $\mathrm{N}_{\gamma}$ for circular and rectangular footings. In Centrifuge 91 (Ko HY and Mclean FG (eds)). Balkema, Rotterdam, the Netherlands, pp. 179-186.

Kutter BL, Moquette O'Leary L, Thompson PY and Lather R (1988) Gravity-scaled tests on blast-induced soil-structure interaction. Journal of Geotechnical Engineering 114(4): 431-447, http://dx.doi. org/10.1061/(ASCE)0733-9410(1988)114:4(431).

Lau CK and Bolton MD (2011a) The bearing capacity of footings on granular soils. II: Experimental evidence. Géotechnique 61(8): 639-650, http://dx.doi.org/10.1680/geot.7.00207.

Lau CK and Bolton MD (2011b) The bearing capacity of footings on granular soils: I: Numerical analysis. Géotechnique 61(8): 627-638, http://dx.doi.org/10.1680/geot.7.00206. 
Lee KK, Cassidy MJ and Randolph MF (2013) Bearing capacity on sand overlying clay soils: experimental and finite element investigation of potential punch-through failure. Géotechnique 63(15): 1271-1284, http://dx.doi.org/10.1680/geot.12.P.175.

Leonards GA (1982) Investigation of failures. Journal of Geotechnical Engineering Division 108(GT2): 222-283.

Lings ML and Dietz MS (2005) The peak strength of sand-steel interfaces and the role of dilation. Soils and Foundations 45(6): 1-14, http://doi. org/10.3208/sandf.45.1.

Loukidis D and Salgado R (2009) Bearing capacity of strip and circular footings in sand using finite elements. Computers and Geotechnics 36(5): 871-879, http://dx.doi.org/10.1016/j.compgeo. 2009.01.012.

Loukidis D and Salgado R (2011) Effect of relative density and stress level on the bearing capacity of footings on sand. Géotechnique 61(2): 107-119, http://dx.doi.org/10.1680/geot.8.P.150.3771.

Mabrouki A, Benmeddour D, Frank R and Mellas M (2010) Numerical study of the bearing capacity for two interfering strip footings on sands. Computers and Geotechnics 37(4): 431-439, http://dx.doi.org/ 10.1016/j.compgeo.2009.12.007.

McMahon BT and Bolton MD (2011) Experimentally observed settlements beneath shallow foundations on sand. In Proceedings of the 15th European Conference on Soil Mechanics and Geotechnical Engineering (Anagnostopoulos A, Pachakis M and Tsatsanifos C (eds)). IOS Press, Amsterdam, the Netherlands, vol. 1, pp. 749-754.

Meyerhof GG (1951) The ultimate bearing capacity of foundations. Géotechnique 2(4): 301-332, http://dx.doi.org/10.1680/geot.1951.2.4. 301.

Mikasa M and Takasa N (1973) Significance of centrifugal model test in soil mechanics. Proceedings of the 8th International Conference on Soil Mechanics and Foundation Engineering, Moscow, Russia, vol. 1.2 , pp. $273-278$.

Muhs H (1965) Discussion on: 'The scale effect on the phenomenon of progressive rupture in cohesionless soils by de Beer EE, Proceedings of the 6th ICSMFE, Montreal, vol. 2, pp. 13-17'. Proceedings of the 6th ICSMFE, Montreal, QC, Canada, vol. 3, pp. 419-421.

Ng CWW (2014) The state-of-the-art centrifuge modelling of geotechnical problems at HKUST. Journal of Zhejiang University - Science A 15(1): $1-21$

Ovesen NK (1975) Centrifugal testing to bearing capacity problems of footings on sand. Géotechnique 25(2): 394-401, http://dx.doi.org/10. 1680/geot.1975.25.2.394

Plaxis (2008) Plaxis 2D, Version 8.6. Plaxis, Delft, the Netherlands. See http://www.plaxis.nl/ (accessed 15/02/2017).

Potts DM (2003) Numerical analysis: a virtual dream or practical reality? Géotechnique 53(6): 535-573, http://dx.doi.org/10.1680/geot.2003.53. 6.535 .

Potts DM and Zdravkovic L (1999) Finite Element Analysis in Geotechnical Engineering: Theory. Thomas Telford, London, UK.

Potts DM and Zdravkovic L (2001) Finite Element Analysis in Geotechnical Engineering: Application. Thomas Telford, London, UK.

PrandtI L (1920) Über die härte plastischer körper. Nachrichten von der Königlichen Gesellschaft der Wissenschaften zu Göttingen. In Mathematisch-Physikalische Klasse. Weidmannsche Buchhandlung, Berlin, Germany, pp. 74-85 (in German).

Pu JL and Ko HY (1988) Experimental determination of bearing capacity in sand by centrifuge model tests. In Proceedings of International Conference on Geotechnical Centrifuge Modelling, Centrifuge '88, Paris (Corté JF (ed.)). Balkema, Rotterdam, the Netherlands, pp. 307-311.

Roscoe KH (1970) The influence of strains in soil mechanics. Géotechnique 20(2): 129-170, http://dx.doi.org/10.1680/geot.1970.20.2.129.

Rowe PW (1969) The relation between the shear strength of sands in triaxial compression, plane strain and direct shear. Géotechnique 19(1): 75-86, http://dx.doi.org/10.1680/geot.1969.19.1.75.
Rowe PW (1972) The relevance of soil fabric to site investigation practice. Géotechnique 22(2): 195-300, http://dx.doi.org/10.1680/geot. 1972.22.2.195.

Salgado R (2008) The Engineering of Foundations. McGraw-Hill, New York, NY, USA.

Schofield AN (1980) Cambridge Geotechnical Centrifuge operations. Géotechnique 30(3): 227-268, http://dx.doi.org/10.1680/geot.1980.30. 3.227 .

Shiraishi S (1990) Variation in bearing capacity factors of dense sand assessed by model loading tests. Soils and Foundations 30(1): 17-26, http://doi.org/10.3208/sandf1972.30.17.

Siddiquee MSA, Tanaka T, Tatsuoka F, Tani K and Morimoto T (1999) Numerical simulation of bearing capacity characteristics of strip footing on sand. Soils and Foundations 39(4): 93-109, http://doi.org/ 10.3208/sandf.39.4 93

Siddiquee MSA, Tatsuoka F, Tanaka T et al. (2001) Model tests and FEM simulation of some factors affecting the bearing capacity of a footing on sand. Soils and Foundations 41(2): 53-76, http://doi.org/10.3208/ sandf.41.2 53 .

Tatsuoka F (2001) Impacts on geotechnical engineering of several recent findings from laboratory stress-strain tests on geomaterials. In The 2000 Burmister Lecture at Columbia University, Geotechnics for Roads, Rail Tracks and Earth Structures (Gomez Correia A and Brandle H (eds)). Balkema, Rotterdam, the Netherlands, pp. 69-140.

Tatsuoka F, Goto S and Sakamoto M (1986a) Effect of some factors on strength and deformation characteristics of sand at low pressures. Soils and Foundations 26(1): 105-114, http://doi.org/10.3208/sandf1972.26. 105.

Tatsuoka F, Sakamoto M, Kawamura T and Fukushima S (1986b) Strength and deformation characteristics of sand in plane strain compression at extremely low pressures. Soils and Foundations 26(1): 65-84, http:// doi.org/10.3208/sandf1972.26.65.

Tatsuoka F, Okahara M, Tanaka T et al. (1991) Progressive failure and particle size effect in bearing capacity of a footing on sand. In Proceedings of ASCE Geotechnical Engineering Congress, 1991. American Society of Civil Engineers, Reston, VA, USA, ASCE Geotechnical Special Publication no. 27, pp. 788-802.

Terzaghi K (1929) Effects of minor geologic details on the safety of dams. In Geology and Engineering for Dams and Reservoirs. American Institute of Mining and Metallurgical EngineersTechnical Publication 215, pp. 31-44. Reprinted in Terzaghi K (1960) From Theory to Practice in Soil Mechanics: Selections from the Writings of Karl Terzaghi. Wiley, New York, NY, USA, pp. 119-132.

Terzaghi K (1943) Theoretical Soil Mechanics. Wiley, New York, NY, USA Toyosawa Y, Itoh K, Kikkawa N, Yang JJ and Liu F (2013) Influence of model footing diameter embedded depth on particle size effect in centrifugal bearing capacity test. Soils and Foundations 53(2): 349-356, http://dx.doi.org/10.1016/j.sandf.2012.11.027.

Ueno K, Miura K and Maeda Y (1998) Prediction of ultimate bearing capacity of surface footings with regard to size effects. Soils and Foundations 38(3): 165-178, http://doi.org/10.3208/sandf.38.3 165.

Ueno K, Miura K, Kusakabe O and Nishimura M (2001) Reappraisal of size effect of bearing capacity from plastic solution. Journal of Geotechnical and Geoenvironmental Engineering 127(3): 275-281, http://dx.doi.org/10.1061/(ASCE)1090-0241(2001)127:3(275).

Valore C and Ziccarelli M (2009) The evolution of grain-size distribution of sands under 1-D compression. In Proceedings of the 17th International Conference on Soil Mechanics and Geotechnical Engineering (Hamza M, Shahien M and El-Mossallamy Y (eds)). IOS Press, Amsterdam, the Netherlands, vol. 1, pp. 84-88.

Valore C, Ziccarelli M and Muscolino SR (2017) The bearing capacity of footings on sand with a weak layer. Geotechnical Research, http://dx. doi.org/10.1680/jgere.16.00020.

Vesić AS (1973) Analysis of ultimate loads of shallow foundations. Journal of the Geotechnical Engineering Division 99(SM1): 45-73. 
Geotechnical Research

Volume 4 Issue GR1
Centrifuge tests on strip footings on sand

with a weak layer

Ziccarelli, Valore, Muscolino and Fioravante
Vesić AS (1975) Bearing capacity of shallow foundations. In Foundations Engineering Handbook (Winterkorn HF and Fang HY (eds)). Van Nostrand Reinhold, New York, NY, USA, pp. 121-147.

White DJ, Teh KL, Leung CF and Chow YK (2008) A comparison of the bearing capacity of flat and conical circular foundations on sand. Géotechnique 58(10): 781-792, http://dx.doi.org.10.1680/geot.8.D. 024.

Yamaguchi H, Kimura T and Fuji-i N (1976) On the influence of progressive failure on the bearing capacity of shallow foundations in dense sand. Soils and Foundations 16(4): 11-22, http://doi.org/10. 3208/sandf1972.16.4 11.
Yamaguchi H, Kimura T and Fuji-i N (1977) On the scale effect of footings in dense sand. Proceedings of the 9th ICSMFE, Tokyo, Japan, vol. 2, pp. 795-798.

Yin JH, Wang YJ and Selvadurai APS (2001) Influence of nonassociativity on the bearing capacity of a strip footing. Journal of Geotechnical and Geoenvironmental Engineering 127(11): 985-989, http://dx.doi.org/10. 1061/(ASCE)1090-0241(2001)127:11(985).

Zhu F, Clark JI and Phillips R (2001) Scale effect of strip and circular footings resting on dense sand. Journal of Geotechnical Engineering 127(7): 613-621, http://dx.doi.org/10.1061/(ASCE)1090-0241(2001) 127:7(613).

\section{How can you contribute?}

To discuss this paper, please submit up to 500 words to the editor at journals@ice.org.uk. Your contribution will be forwarded to the author(s) for a reply and, if considered appropriate by the editorial board, it will be published as discussion in a future issue of the journal. 